\title{
Optimal reactive power dispatch using a novel optimization algorithm
}

\author{
Ranjit Roy ${ }^{1 *}$, Tanmay Das ${ }^{2}$ and Kamal Krishna Mandal ${ }^{2}$
}

\author{
${ }^{*}$ Correspondence: \\ rroy.tigchaibasa@gmail.com \\ ${ }^{1}$ Department of Electrical \\ Engineering, Chaibasa \\ Engineering College, \\ Chaibasa, Jharkhand, India \\ Full list of author information \\ is available at the end of the \\ article
}

\begin{abstract}
The problem of optimal reactive power dispatch (ORPD) is one of the most popular and widely discussed problem in power system engineering all over the world. Optimal reactive power dispatch is one of the sub-problems of the optimal power flow which is complex and nonlinear problem, which can be formulated as both single- and multiobjective. In this paper, the problem has been formulated as a single-objective problem to minimize the active power losses in the transmission lines. A recently proposed powerful and reliable meta-heuristic algorithm known as the JAYA algorithm has been applied to solve the ORPD problem. The algorithm has been applied on the standard IEEE 14, 30, 57 and 118 bus systems. The simulation results using the proposed algorithm when compared with the results from other algorithms and few others reported in the literature prove that the JAYA algorithm is the most superior among all.
\end{abstract}

Keywords: Active power loss, JAYA algorithm, Optimization problem, ORPD, Particle swarm optimization, Variants of PSO, Transmission line losses

\section{Introduction}

The major challenges in power system engineering nowadays is the large expansion of power and the system stability accompanied with it. The large variation in the time variant load demand results in system instability leading to voltage collapse and blackout. Another major problem is the increase in the active power losses in the transmission line, which results in low efficiency of the system and thus restrict the expansion of power to a certain limit. The ORPD problem is a complex and nonlinear problem in power system engineering which helps in enhancing the security of the power system and improving its economy largely. The solution of the ORPD problem is to minimize the objective function by satisfying the operating constraints. It helps in optimally redistributing the reactive power in the system resulting in minimization of transmission line active power losses and improving the voltage profile in the system. Due to this nonlinearity of the problem, many conventional techniques of optimization like the Newton method, quadratic programming, linear programming and interior point methods have failed to solve the ORPD problem due to their low accuracy, complexity, inability to find the local and global optima and thus resulting in secure converge [1-4]. Thus, to overcome these disadvantages, many modern stochastic and meta-heuristic techniques have been developed in the recent past such as the genetic algorithm (GA) [5], improved GA

(c) The Author(s), 2021. Open Access This article is licensed under a Creative Commons Attribution 4.0 International License, which permits use, sharing, adaptation, distribution and reproduction in any medium or format, as long as you give appropriate credit to the original author(s) and the source, provide a link to the Creative Commons licence, and indicate if changes were made. The images or other third party material in this article are included in the article's Creative Commons licence, unless indicated otherwise in a credit line to the material. If material is not included in the article's Creative Commons licence and your intended use is not permitted by statutory regulation or exceeds the permitted use, you will need to obtain permission directly from the copyright holder. To view a copy of this licence, visit http:// creativecommons.org/licenses/by/4.0\%. 
[6], particle swarm optimization (PSO) [7], evolutionary programming (EP) [8], hybrid evolutionary strategy [9], seeker optimization algorithm (SOA) [10], bacterial-foraging optimization (BFO) [11], gravitational search algorithm (GSA) [12], differential evolution (DE) [13] and Artificial Bee colony algorithm (ABC) [14]. to solve the ORPD problem. Recently in [15], the Whale optimization algorithm inspired from the bubble-net hunting technique of the humpback whales has been used to solve the ORPD problem. Shaheen et al. [16] proposed a backtracking search optimizer (BSO) where five diversified generation strategies of mutation factor have been applied to solve the ORPD problem. In [17], Lenin proposed an algorithm named Enhanced Red Wolf Optimization which is a hybrid of wolf optimization (WO) and particle swarm optimization (PSO) algorithm to solve the ORPD problem. In [18], an improved social spider optimization (ISSO) has been used for determining the optimal solution to the power loss in ORPD problem. Li et al. [19], proposed an Antlion optimization algorithm (IALO) top solve the ORPD problem for three bus systems. In [20], two different algorithms namely the Moth-Flame optimizer and Antlion optimizer have been used to optimize the ORPD problem.

In this paper, a novel algorithm named the JAYA algorithm, developed by Rao [21] has been applied to solve the ORPD problem. It is a newly developed optimization technique and has capability in optimizing any objective function under any possible constraint. Many other algorithms such as PSO and its many other different variants, which are R-PSO, L-PSO, PSO-CFA, Improved PSO Based on Success Rate (IPSO-SR) [22], Fruit Fly optimization algorithm (FOA) [23] and Modified Fruit Fly optimization algorithm (MFOA) [24] are also tested along with JAYA algorithm. The objective of this work is to minimize the transmission line power loss by optimal allocation of the control variables within the system without violating the equality and inequality constraints. The control variables are the generator voltage, tap position of the tap-changing transformer and the VAR outputs of the reactive power compensating devices situated at few specific buses. The algorithms have been used to solve the ORPD problem under four different test cases, IEEE 14, 30, 57 and 118. Here, two different limits of the control variables for the IEEE 30, 57 and 118 bus systems each have been used as per the literature survey to solve the ORPD problem. The results for each cases are compared to determine the best technique among them in terms of convergence rate, ability to determine the optimal solution and robustness.

\section{Problem formulation}

This paper aims at minimizing the active power loss in the transmission lines by determining the optimal solutions to the ORPD problem. The proposed JAYA algorithm helps in determining the optimal values of the control variables while simultaneously satisfying all the constraints in the system. The objective function of the ORPD problem is shown below [25]:

$$
f_{n}=\min \left(P_{\text {loss }}\right)=\sum_{k=1}^{N l} G_{k}\left(V_{i}^{2}+V_{j}^{2}-2 V_{i} V_{j} \cos \delta_{i j}\right)
$$


where, $\mathrm{Nl}$ represent the total number of transmission lines, the conductance of the $k$ th branch is shown as $G_{k}, V_{i}$ and $V_{j}$ represent the magnitudes of the bus voltage for the buses $i$ and $j$, respectively, and $\delta_{i j}$ stand for the phase difference between $V_{i}$ and $V_{j}$.

\section{Constraints}

The following shows the different constraints of the objective function:

\section{Equality constraints}

$$
\begin{aligned}
& P_{g i}-P_{d i}-V_{i} \sum_{j=1}^{N b} V_{j}\left(G_{i j} \cos \theta_{i j}+B_{i j} \sin \theta_{i j}\right)=0 \\
& Q_{g i}-Q_{d i}-V_{i} \sum_{j=1}^{N b} V_{j}\left(G_{i j} \cos \theta_{i j}+B_{i j} \sin \theta_{i j}\right)=0
\end{aligned}
$$

The above constraints depict the load flow equations, where $N b$ represent the total number of buses, $P_{g i}$ and $Q_{g i}$ represent the active and reactive power generation and $P_{d i}$ and $Q_{d i}$ are the active and reactive power load demands at the $i$ th bus, respectively. $G_{i j}$ and $B_{i j}$ represent the conductance and susceptance between two different buses (i.e., $i$ th and $j$ th), respectively, and $\theta_{i j}$ is the angle between the $i$ th and $j$ th bus.

\section{Inequality constraints}

- Generator constraints

The generator active power, reactive power and voltage magnitudes are restricted within their limits and must not be violated during solving the problem. The limits are shown below:

$$
\begin{gathered}
V_{g i}^{\min } \leq V_{g i} \leq V_{g i}^{\max }, \quad i=1, \ldots, N_{g} \\
P_{g i}^{\min } \leq P_{g i} \leq P_{g i}^{\max }, \quad i=1, \ldots, N_{g} \\
Q_{g i}^{\min } \leq Q_{g i} \leq Q_{g i}^{\max }, \quad i=1, \ldots, N_{g}
\end{gathered}
$$

where, $N_{g}$ represent the total number of generator buses, $V_{g i}^{\min }, P_{g i}^{\min }$ and $Q_{g i}^{\min }$ are the minimum limits and $V_{g i}^{\max }, P_{g i}^{\max }$ and $Q_{g i}^{\max }$ are the maximum limits of the generator bus voltages, active and reactive power, respectively. $V_{g i}, P_{g i}$ and $Q_{g i}$ are the amount of voltage, active and reactive power generation at the $i$ th bus.

- Transformer constraints

The minimum and maximum limits of the settings of the tap-changing transformer are given by:

$$
T_{i}^{\min } \leq T_{i} \leq T_{i}^{\max }, \quad i=1, \ldots, N_{T}
$$


where, $N_{T}$ shows the number of tap-changing transformers in the system. $T_{i}$ is the tap-setting position value of the tap-changing transformer at the $i$ th bus and $T_{i}^{\mathrm{min}}$, $T_{i}^{\max }$ are its minimum and maximum limits.

- VAR compensator constraints

The limits of the reactive power to be injected by the VAR compensators are given as:

$$
Q_{c i}^{\min } \leq Q_{c i} \leq Q_{c i}^{\max }, \quad i=1, \ldots, N_{C}
$$

where, $N_{C}$ represent the total number of shunt compensators at the buses and $Q_{c i}^{\min }, Q_{c i}^{\max }$ are the minimum and maximum limits of the reactive power injection $Q_{c i}$, respectively.

\section{- Operating constraints}

The voltage at the load buses and the apparent power at the branches must remain within a specified limit. Their limits are shown below:

$$
\begin{aligned}
& V_{L i}^{\min } \leq V_{L i} \leq V_{L i}^{\max }, \quad i=1, \ldots, N_{P Q} \\
& S_{L i} \leq S_{L i}^{\max }, \quad i=1, \ldots, N L
\end{aligned}
$$

where, $N_{P Q}$ depict the total number of load buses, and $S_{L i}^{\max }$ is the maximum value of the apparent power flow at the $i$ th bus where $S_{L i}$ is the apparent power at that branch. $V_{L i}$ is the magnitude of the voltage at the $i$ th load bus and $V_{L i}^{\min }, V_{L i}^{\max }$ are its minimum and maximum limits.

Among all the mentioned variables, the load bus voltages, the reactive power generation and apparent power flow are the dependent variables considered. These variables are constrained using penalty coefficients to the objective function in Eq. (1). Thus, the objective function modified as,

$$
f=P_{\text {loss }}+\lambda_{V} \sum_{i=1}^{N_{V} \lim }\left(V_{i}-V_{i}^{\lim }\right)^{2}+\lambda_{Q} \sum_{i=1}^{N_{Q} \lim }\left(Q_{g i}-Q_{g i}^{\lim }\right)^{2}
$$

The limits of $V_{i}^{\lim }$ and $Q_{g i}^{\lim }$ are:

$$
\begin{gathered}
V_{i}^{\lim }=\left\{\begin{array}{l}
V_{i}^{\min }, \text { if } V_{i}<V_{i}^{\min } \\
V_{i}^{\max }, \text { if } V_{i}>V_{i}^{\max }
\end{array}\right. \\
Q_{g i}^{\lim }=\left\{\begin{array}{l}
Q_{g i}^{\min }, \text { if } Q_{g i}<Q_{g i}^{\min } \\
Q_{g i}^{\max }, \text { if } Q_{g i}>Q_{g i}^{\max }
\end{array}\right.
\end{gathered}
$$

where, $\lambda_{V}$ and $\lambda_{Q}$ are penalty coefficients, $N_{V}^{\mathrm{lim}}$ is the number of buses on which the voltages are outside limits and $N_{Q}^{\mathrm{lim}}$ is the number of buses on which the reactive power generations are outside limits. 


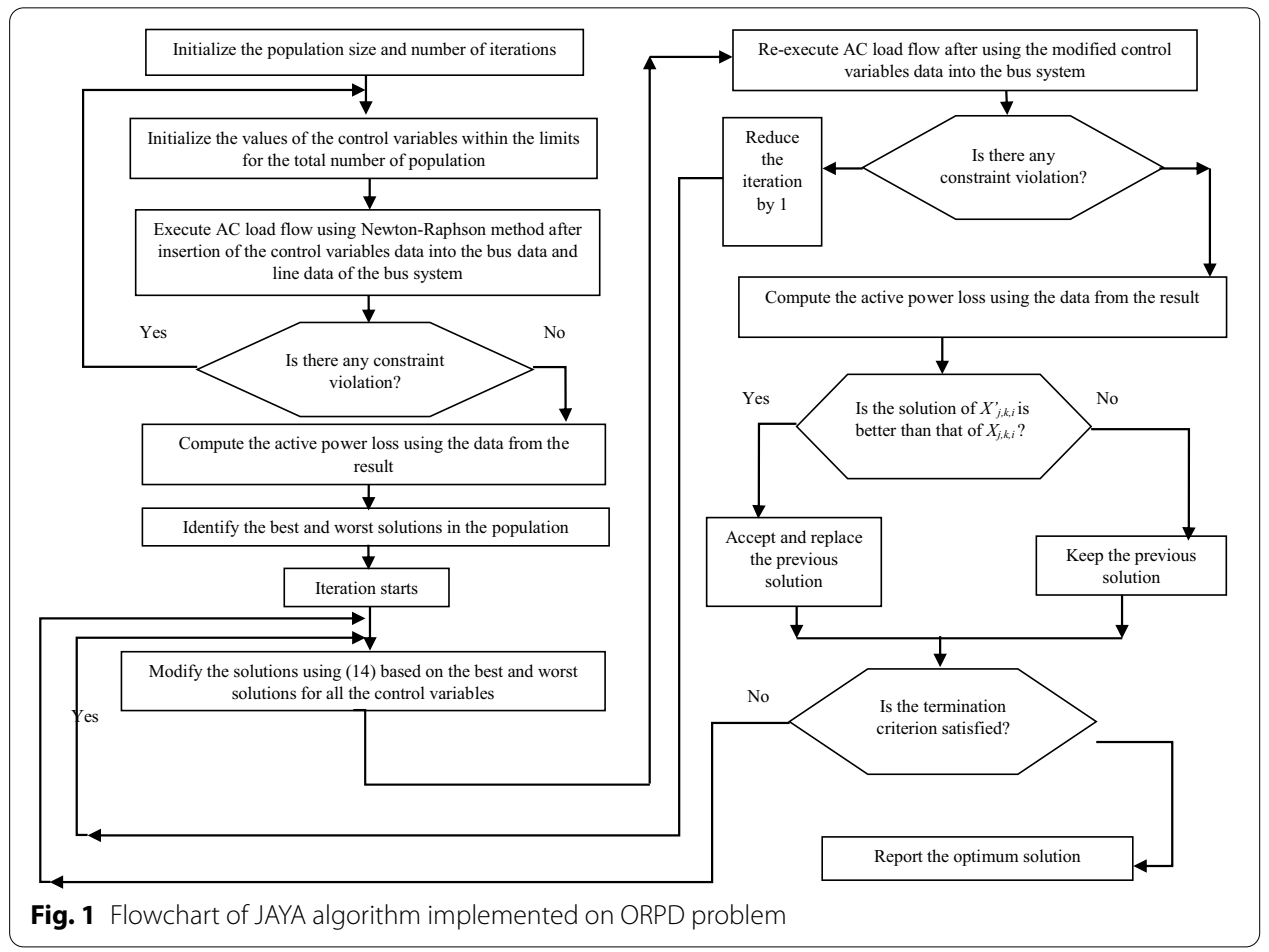

\section{JAYA algorithm}

The JAYA algorithm is a newly proposed meta-heuristic algorithm by Rao [21], which is used for solving any complex, nonlinear and stochastic problem like the ORPD. This algorithm has the ability to find a quick optimal solution to any problem and has a very high convergence rate. It has a high success rate in determining the best solution to the problems compared to many other algorithms as it has a tendency to move toward the best solution in every iteration and move away from the worst. Thus, this reduces the chance of the algorithm to be stuck into the global optima and keeps updating its solution comparing with the best.

For an objective function $f(x)$, let there be ' $m$ ' number of design variables (i.e., $j=1$, $2, \ldots, \mathrm{m})$ and ' $n$ ' number of populations $(k=1,2, \ldots, \mathrm{n})$ for $i$ th iteration. Let the population having the best solution of $f(x)$ (i.e., $f(x)_{\text {best }}$ ) be called the best candidate and for the population having the worst solution to the objective function (i.e., $f(x)_{\text {worst }}$ ) be called worst. Let the value for the $j$ th variable for the $k$ th population in the $i$ th iteration be represented as $A_{j, k, i}$. Then, the value is modified as given in Eq. (14).

$$
A_{j, k, i}^{\prime}=A_{j, k, i}+r_{1}\left(A_{j, \text { best }, i}-\left|A_{j, k, i}\right|\right)-r_{2}\left(A_{j, \text { worst }, i}-\left|A_{j, k, i}\right|\right)
$$

where, $A_{j, \text { best }, i}$ and $A_{j, \text { worst }, i}$ are the best and the worst solution of the objective function of the $j$ th variable, respectively. $r_{1}$ and $r_{2}$ are two random numbers in the range $[0,1]$. The equation for updating the variable shows the tendency of the algorithm to move closer to the best solution and the tendency of the variable to move away from the worst solution. Thus, this helps in updating the control variables much more accurately and results in obtaining the most optimal result for the optimizing 
Table 1 The comparative results of G01-G24 benchmark functions using different algorithms

\begin{tabular}{|c|c|c|c|c|c|c|c|c|}
\hline Function & & PSO & BBO & $\mathrm{DE}$ & $A B C$ & HTS & TLBO & JAYA \\
\hline G01 & Best & -15 & -14.977 & -15 & -15 & -15 & -15 & -15 \\
\hline$(-15.00)$ & Mean & -14.71 & -14.7698 & -14.555 & -15 & -15 & -10.782 & -15 \\
\hline $\mathrm{G} 02$ & Best & -0.669158 & -0.7821 & -0.472 & -0.803598 & -0.7517 & -0.7835 & -0.803605 \\
\hline$(-0.803619)$ & Mean & -0.41996 & -0.7642 & -0.665 & -0.792412 & -0.6437 & -0.6705 & -0.7968 \\
\hline $\mathrm{G} 03$ & Best & 1 & -1.0005 & -0.99393 & -1 & -1.0005 & -1.0005 & -1.005 \\
\hline$(-1.0005)$ & Mean & 0.764813 & -0.3957 & -1 & -1 & -0.9004 & -0.8 & -1 \\
\hline G04 & Best & $-30,665.539$ & $-30,665.539$ & $-30,665.539$ & $-30,665.539$ & $-30,665.539$ & $-30,665.539$ & $-30,665.539$ \\
\hline$(-30,665.539)$ & Mean & $-30,665.539$ & $-30,411.865$ & $-30,665.539$ & $-30,665.539$ & $-30,665.539$ & $-30,665.539$ & $-30,665.539$ \\
\hline G05 & Best & 5126.484 & 5134.2749 & 5126.484 & 5126.484 & 5126.486 & 5126.486 & 5126.486 \\
\hline-5126.486 & Mean & 5135.973 & 6130.5289 & 5264.27 & 5185.714 & 5126.5152 & 5126.6184 & 5126.5061 \\
\hline G06 & Best & -6961.814 & -6961.8139 & -6954.434 & -6961.814 & -6961.814 & -6961.814 & -6961.814 \\
\hline$(-6961.814)$ & Mean & -6961.814 & -6181.7461 & -6954.434 & -6961.813 & -6961.814 & -6961.814 & -6961.814 \\
\hline G07 & Best & 24.37 & 25.6645 & 24.306 & 24.33 & 24.3104 & 24.3101 & 24.3062 \\
\hline-24.3062 & Mean & 32.407 & 29.829 & 24.31 & 24.473 & 24.4945 & 24.837 & 24.3092 \\
\hline G08 & Best & -0.095825 & -0.095825 & -0.095825 & -0.095825 & -0.095825 & -0.095825 & -0.095825 \\
\hline$(-0.095825)$ & Mean & -0.095825 & -0.95824 & -0.095825 & -0.095825 & -0.095825 & -0.095825 & -0.095825 \\
\hline G09 & Best & 680.63 & 680.6301 & 680.63 & 680.634 & 680.6301 & 680.6301 & 680.6301 \\
\hline-680.6301 & Mean & 680.63 & 692.7162 & 680.63 & 680.634 & 680.6329 & 680.6336 & 680.6301 \\
\hline G10 & Best & 7049.481 & 7679.0681 & 7049.548 & 7053.904 & 7049.4836 & 7250.9704 & 7049.312 \\
\hline-7049.28 & Mean & 7205.5 & 8764.9864 & 7147.334 & 7224.407 & 7119.7015 & 7257.0927 & 7052.7841 \\
\hline G11 & Best & 0.749 & 0.7499 & 0.752 & 0.75 & 0.7499 & 0.7499 & 0.7499 \\
\hline-0.7499 & Mean & 0.749 & 0.83057 & 0.901 & 0.75 & 0.7499 & 0.7499 & 0.7499 \\
\hline $\mathrm{G} 12$ & Best & -1 & -1 & -1 & -1 & -1 & -1 & -1 \\
\hline$(-1)$ & Mean & -0.998875 & -1 & -1 & -1 & -1 & -1 & -1 \\
\hline G13 & Best & 0.085655 & 0.62825 & 0.385 & 0.76 & 0.37319 & 0.44015 & 0.003625 \\
\hline$(-0.05394)$ & Mean & 0.569358 & 1.09289 & 0.872 & 0.968 & 0.66948 & 0.69055 & 0.003627 \\
\hline G14 & Best & -44.9343 & 54.6679 & -45.7372 & -44.6431 & -47.7278 & -46.5903 & -47.7322 \\
\hline$(-47.764)$ & Mean & -40.871 & 175.9832 & -29.2187 & -40.1071 & -46.4076 & -39.9725 & -46.6912 \\
\hline G15 & Best & 961.715 & 962.664 & 961.715 & 961.7568 & 961.715 & 961.715 & 961.715 \\
\hline-961.715 & Mean & 965.5154 & 1001.4367 & 961.7537 & 966.2868 & 961.75 & 962.8641 & 961.715 \\
\hline G16 & Best & -1.9052 & -1.9052 & -1.9052 & -1.9052 & -1.9052 & -1.9052 & -1.9052 \\
\hline$(-1.9052)$ & Mean & -1.9052 & -1.6121 & -1.9052 & -1.9052 & -1.9052 & -1.9052 & -1.9052 \\
\hline G17 & Best & 8857.514 & 9008.5594 & 8854.6501 & 8859.713 & 8853.5396 & 8853.5396 & 8853.5396 \\
\hline-8853.5396 & Mean & 8899.4721 & 9384.268 & 8932.0444 & 8941.9245 & 8877.9175 & 8876.5071 & 8872.5402 \\
\hline G18 & Best & -0.86603 & -0.65734 & -0.86531 & -0.86603 & -0.86603 & -0.86603 & -0.86603 \\
\hline$(-0.86603)$ & Mean & -0.8276 & -0.56817 & -0.86165 & -0.86587 & -0.77036 & -0.86569 & -0.86602 \\
\hline G19 & Best & 33.5358 & 39.1471 & 32.6851 & 33.3325 & 32.7132 & 32.7916 & 32.6803 \\
\hline-32.6555 & Mean & 36.6172 & 51.8769 & 32.768 & 36.0078 & 32.7903 & 34.0792 & 32.7512 \\
\hline $\mathrm{G} 20$ & Best & 0.24743 & 1.26181 & 0.24743 & 0.24743 & 0.24743 & 0.24743 & 0.24139 \\
\hline-0.204979 & Mean & 0.97234 & 1.43488 & 0.26165 & 0.80536 & 0.25519 & 1.22037 & 0.24385 \\
\hline $\mathrm{G} 21$ & Best & 193.7311 & 198.8151 & 193.7346 & 193.7343 & 193.7264 & 193.7246 & 193.5841 \\
\hline-193.274 & Mean & 345.6595 & 367.2513 & 366.9193 & 275.5436 & 256.6091 & 264.6092 & 193.7219 \\
\hline $\mathrm{G} 22$ & Best & -258.74 & -267.15 & -249.12 & -243.43 & -272.78 & -248.78 & -242.45 \\
\hline-236.4309 & Mean & -255.55 & -254.44 & -249.46 & -251.33 & -265.66 & -252.56 & -239.05 \\
\hline G23 & Best & -105.9826 & 2.3163 & -72.642 & -43.2541 & -390.6472 & -385.0043 & -391.5192 \\
\hline$(-400.055)$ & Mean & -25.9179 & 22.1401 & -7.2642 & -4.3254 & -131.2522 & -83.7728 & -381.2312 \\
\hline $\mathrm{G} 24$ & Best & -5.508 & -5.508 & -5.508 & -5.508 & -5.508 & -5.508 & -5.508 \\
\hline$(-5.5080)$ & Mean & -5.508 & -5.4982 & -5.508 & -5.508 & -5.508 & -5.508 & -5.508 \\
\hline
\end{tabular}


Table 2 Typical parameters of the bus systems

\begin{tabular}{lllll}
\hline Control variables & $\begin{array}{l}\text { IEEE } \mathbf{1 4} \text { bus } \\
\text { system }\end{array}$ & $\begin{array}{l}\text { IEEE } \mathbf{3 0} \text { bus } \\
\text { system }\end{array}$ & IEEE 57 bus system & $\begin{array}{l}\text { IEEE } \\
\mathbf{1 1 8} \text { bus } \\
\text { system }\end{array}$ \\
\hline Buses & 14 & 30 & 57 & 118 \\
Generators & 5 & 6 & 7 & 54 \\
Transformers & 3 & 4 & 15 & 9 \\
Shunt compensators & 2 & 3 & 3 & 14 \\
Transmission lines & 20 & 41 & 80 & 186 \\
Control variables & 10 & 13 & 27 & 77 \\
Base $P_{\text {loss }}(\mathrm{MW})$ & 13.49 & 5.66 & 27.8637 & 132.45 \\
\hline
\end{tabular}

Table 3 Simulation results on IEEE 14 bus system using different algorithms

\begin{tabular}{|c|c|c|c|c|c|c|c|c|}
\hline $\begin{array}{l}\text { Control } \\
\text { Variables } \\
\text { (p.u.) }\end{array}$ & PSO & R-PSO & L-PSO & PSO-CFA & IPSO-SR & FOA & MFOA & JAYA \\
\hline$V_{G 1}$ & 1.1 & 1.1 & 1.1 & 1.1 & 1.1 & 1.1 & 1.1 & 1.1 \\
\hline$V_{G 2}$ & 1.1 & 1.1 & 1.1 & 1.1 & 1.0863 & 1.1 & 1.1 & 1.0859 \\
\hline$V_{G 3}$ & 1.0701 & 1.0696 & 1.0703 & 1.0702 & 1.0578 & 1.1 & 1.1 & 1.0568 \\
\hline$V_{G 6}$ & 1.1 & 1.1 & 1.1 & 1.0605 & 1.0575 & 0.9 & 1.1 & 1.1 \\
\hline$V_{G 8}$ & 1.1 & 1.1 & 1.1 & 1.1 & 1.0726 & 0.95 & 1.1 & 1.1 \\
\hline$T_{4-7}$ & 0.9285 & 0.9551 & 1.1 & 1.1 & 0.9685 & 1.1 & 1.1 & 0.9492 \\
\hline $\mathrm{T}_{4-9}$ & 1.1 & 1.1 & 0.9 & 0.9 & 1.1 & 0.935 & 1.1 & 1.0766 \\
\hline$T_{5-6}$ & 1.1 & 1.0179 & 1.0047 & 1.1 & 1.1 & 1.1 & 1.1 & 1.0031 \\
\hline $\mathrm{Q}_{\mathrm{sc} 9}$ & 0.2332 & 0.3 & 0.2643 & 0.015 & 0.2134 & 0.000328 & 0.0443 & 0.3 \\
\hline $\mathrm{Q}_{\mathrm{sc} 14}$ & 0.0555 & 0.0604 & 0.0 & 0.0641 & 0.0634 & 0.000296 & 0.0443 & 0.0594 \\
\hline $\begin{array}{l}\text { Total } P_{\text {loss }} \\
(\mathrm{MW})\end{array}$ & 12.4268 & 12.3585 & 12.4041 & 12.416 & 12.2957 & 12.5992 & 12.7531 & 12.2270 \\
\hline $\mathrm{DE}[25]$ & $\mathrm{ABC}[25]$ & ACOR [25] & TLA [25] & DE [25] & MTLA [25] & $\begin{array}{l}\text { MTLA-DDE } \\
{[25]}\end{array}$ & LCA [25] & CSS [25] \\
\hline 13.1053 & 12.9333 & 13.1226 & 12.9229 & 13.1053 & 12.9106 & 12.8978 & 12.9891 & 12.9748 \\
\hline BRCFF [25] & $\mathrm{BB}-\mathrm{BC}$ [25] & PBIL [25] & DDE [25] & TLBO [28] & $\begin{array}{l}\text { BBPSO } \\
{[28]}\end{array}$ & BBDE [28] & GBTLBO [28] & $\begin{array}{l}\text { MGBTLBO } \\
{[28]}\end{array}$ \\
\hline 12.9264 & 13.0039 & 13.0008 & 12.9286 & 12.9878 & 12.9919 & 12.9973 & 12.4152 & 12.3105 \\
\hline PSO [15] & $\begin{array}{l}\text { PSO-TVAC } \\
{[15]}\end{array}$ & WOA [15] & MDE [16] & $\begin{array}{l}\text { SARGA } \\
{[16]}\end{array}$ & RTS [16] & EP [16] & BSO 1 [16] & BSO 2 [16. \\
\hline 12.381 & 12.279 & 12.255 & 13.0532 & 13.21643 & 13.236 & 13.3462 & 12.4633 & 12.4672 \\
\hline BSO 3 [16] & BSO 4 [16] & BSO 4 [16] & & & & & & \\
\hline 12.4651 & 12.4588 & 12.4699 & & & & & & \\
\hline
\end{tabular}

problem compared to many other modern meta-heuristic algorithms. Hence, the JAYA algorithm is one of the most competitive algorithms among the newly developed meta-heuristic optimization algorithms in the recent past. The procedure for the implementation of the JAYA algorithm in solving the ORPD problem is shown in the flowchart in Fig. 1 [26]. 


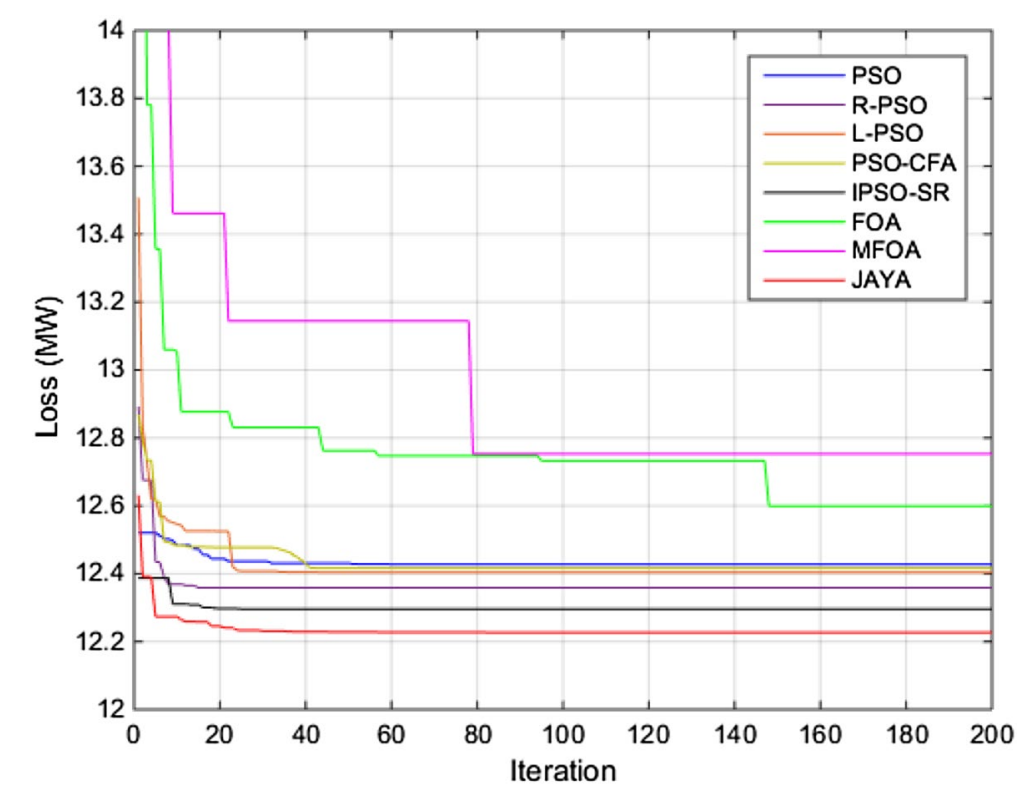

Fig. 2 Convergence characteristic of the algorithms for IEEE 14 bus system

Table 4 Control variable limits (p.u.) for different test cases

\begin{tabular}{lllllllll}
\hline Case no & $\boldsymbol{V}_{\boldsymbol{g}}^{\min }$ & $\boldsymbol{V}_{\boldsymbol{g}}^{\max }$ & $\boldsymbol{V}_{\boldsymbol{P Q}}^{\min }$ & $\boldsymbol{V}_{\boldsymbol{P Q}}^{\max }$ & $T^{\min }$ & $T^{\max }$ & $\mathbf{Q}_{\boldsymbol{c}}^{\min }$ & $\mathbf{Q}_{\boldsymbol{c}}^{\max }$ \\
\hline 1 & 0.9 & 1.1 & 0.95 & 1.05 & 0.95 & 1.05 & -0.12 & 0.36 \\
2 & 0.95 & 1.1 & 0.95 & 1.1 & 0.9 & 1.1 & 0 & 0.36 \\
\hline
\end{tabular}

\section{Simulation results and discussion}

Before going in to the ORPD problem, the proposed JAYA algorithm has been tested on different standard constrained benchmark functions to inspect the optimizing capability of the algorithm. The test have been done to determine the best and the mean values of the solutions for all the respective optimizing functions. The results are compared with many other popular optimization techniques and are shown in Table 1 . The results show that the JAYA algorithm has given the best results compared to the others, and is the most consistent in optimizing any objective function with minimum deviation of the solutions as the mean values are very close to the best solutions for every corresponding functions.

The proposed JAYA algorithm along with few other algorithms as discussed in the literature, are tested on four standard IEEE bus systems, IEEE 14, 30, 57 and 118 bus systems are used as test systems to solve the ORPD problem for active power loss minimization in the transmission lines. In order to get a better comparison between the algorithms, two different cases each for IEEE 30, 57 and 118 bus systems are taken by changing the lower and upper limits of the control variables. The results are tabulated for all the different cases and are compared to establish the superiority of the proposed algorithm among the others in optimizing this minimization problem of ORPD. The software used for this problem is 
Table 5 Simulation results on IEEE 30 bus system using different algorithms for case 1

\begin{tabular}{|c|c|c|c|c|c|c|c|c|}
\hline $\begin{array}{l}\text { Control } \\
\text { Variables } \\
\text { (p.u.) }\end{array}$ & PSO & R-PSO & L-PSO & PSO-CFA & IPSO-SR & FOA & MFOA & JAYA \\
\hline$V_{G 1}$ & 1.1 & 1.1 & 1.1 & 1.1 & 1.1 & 0.9 & 0.9 & 1.1 \\
\hline$V_{G 2}$ & 1.1 & 1.1 & 1.1 & 1.1 & 1.1 & 0.9 & 0.9 & 1.0946 \\
\hline$V_{G 5}$ & 1.1 & 1.0881 & 1.1 & 1.1 & 1.1 & 0.9 & 0.9 & 1.0753 \\
\hline$V_{G 8}$ & 1.0895 & 1.1 & 1.0904 & 1.0903 & 1.1 & 0.9 & 0.9 & 1.0771 \\
\hline$V_{G 11}$ & 1.1 & 1.1 & 1.1 & 1.1 & 1.1 & 1.1 & 0.9 & 1.1 \\
\hline$V_{G 13}$ & 1.1 & 1.1 & 1.1 & 1.1 & 1.1 & 1.0124 & 0.9 & 1.1 \\
\hline$T_{6-9}$ & 1.05 & 1.05 & 1.05 & 1.05 & 1.05 & 0.95 & 0.95 & 1.0318 \\
\hline$T_{6-10}$ & 1.05 & 1.05 & 1.05 & 0.9956 & 1.05 & 0.95 & 0.95 & 0.95 \\
\hline$T_{4-12}$ & 1.05 & 1.05 & 1.05 & 1.05 & 1.05 & 0.95 & 0.95 & 0.9500 \\
\hline$T_{28-27}$ & 1.05 & 1.05 & 1.05 & 1.05 & 1.0025 & 0.9 & 0.95 & 0.955 \\
\hline $\mathrm{Q}_{\mathrm{sc} 3}$ & -0.0124 & -0.0081 & -0.0122 & 0.0012 & -0.0092 & 0.0002 & -0.12 & 0.0807 \\
\hline $\mathrm{Q}_{\mathrm{sc10}}$ & -0.1725 & 0.1543 & 0.1602 & 0.0842 & 0.2177 & 0.0005 & -0.12 & 0.2806 \\
\hline $\mathrm{Q}_{\mathrm{sc} 24}$ & 0.1137 & 0.1165 & 0.1181 & 0.1202 & 0.1016 & 0.0011 & -0.12 & 0.0985 \\
\hline$P_{\text {loss }}(M W)$ & 4.8578 & 4.8488 & 4.8571 & 4.8523 & 4.8304 & 7.1480 & 4.8585 & 4.5990 \\
\hline $\mathrm{ACO}_{\mathrm{R}}[25]$ & $\mathrm{ABC}[25]$ & LCA [25] & CSS [25] & BRCFF [25] & $\mathrm{BB}-\mathrm{BC}[25]$ & PBIL [25] & TLA [25] & DE [25] \\
\hline 4.9147 & 4.9064 & 4.9092 & 4.9062 & 4.9059 & 4.9080 & 4.9144 & 4.9047 & 4.9121 \\
\hline MTLA [25] & DDE [25] & $\begin{array}{l}\text { MTLA-DDE } \\
{[25]}\end{array}$ & TLBO [28] & BBPSO [28] & BBDE [28] & GBTLBO [28] & $\begin{array}{l}\text { MGBTLBO } \\
{[28]}\end{array}$ & SGA [29] \\
\hline 4.8616 & 4.8623 & 4.8596 & 4.8787 & 4.8922 & 4.9015 & 4.8685 & 4.7802 & 4.9800 \\
\hline $\begin{array}{l}\text { MAPSO } \\
{[29]}\end{array}$ & HSA [30] & ICA [31] & IWO [31] & $\begin{array}{l}\text { MICA-IWO } \\
\text { [31] }\end{array}$ & BSO 1 [16] & BSO 2 [16] & BSO 3 [16] & BSO 4 [16] \\
\hline 4.8747 & 4.9059 & 4.8637 & 4.9344 & 4.8599 & 4.6847 & 4.6826 & 4.6728 & 4.6499 \\
\hline \multicolumn{9}{|l|}{ BSO 5 [16] } \\
\hline 4.634 & & & & & & & & \\
\hline
\end{tabular}

MATLAB 2014b, where the algorithms are tested taking the population size to be 100 for all the cases mentioned in the paper. The system data of these test systems are obtained from [27]. The total number of individual parameters used for the test systems are listed in Table 2.

\section{IEEE 14 bus system}

The IEEE-14 bus has five generators at the buses 1 (which is the slack bus), 2, 3, 6 and 8. It has three tap-changing transformers placed branches between the lines (4-7, 4-9 and 5-6) out of the total 20 number of branches. The reactive powers are injected at buses 9 and 14. The limits of the control variables (p.u. value) for IEEE 14 bus system are as follows:

$$
\begin{aligned}
& 0.95 \leq V_{g i} \leq 1.1 \\
& 0.95 \leq V_{L i} \leq 1.05 . \\
& 0.9 \leq T_{i} \leq 1.1 \\
& 0 \leq Q_{c i} \leq 0.3
\end{aligned}
$$

The ORPD problem is solved using all the mentioned algorithms for determining the best solution of the real power loss for the optimal values of the control variables. The simulation results of the algorithms are shown in Table 3, and the convergence characteristic is shown in Fig. 2. The results describe the superiority 
Table 6 Simulation results on IEEE 30 bus system using different algorithms for case 2

\begin{tabular}{|c|c|c|c|c|c|c|c|c|}
\hline $\begin{array}{l}\text { Control } \\
\text { variables } \\
\text { (p.u.) }\end{array}$ & PSO & R-PSO & L-PSO & PSO-CFA & IPSO-SR & FOA & MFOA & JAYA \\
\hline$V_{G 1}$ & 1.1 & 1.1 & 1.1 & 1.1 & 1.1 & 0.9757 & 0.95 & 1.1 \\
\hline$V_{G 2}$ & 1.1 & 1.1 & 1.1 & 1.1 & 1.1 & 0.95 & 0.95 & 1.0945 \\
\hline$V_{G 5}$ & 1.1 & 1.1 & 1.1 & 1.0806 & 1.1 & 0.95 & 0.95 & 1.0752 \\
\hline$V_{G 8}$ & 1.1 & 1.1 & 1.1 & 1.0821 & 1.0882 & 0.95 & 0.95 & 1.077 \\
\hline$V_{G 11}$ & 1.1 & 1.1 & 1.1 & 1.1000 & 1.1 & 1.1 & 0.95 & 1.1 \\
\hline$V_{G 13}$ & 1.1 & 1.1 & 1.1 & 1.1000 & 1.1 & 1.1 & 0.95 & 1.1 \\
\hline$T_{6-9}$ & 0.9981 & 1.1 & 1.1 & 0.9777 & 0.9758 & 0.9 & 0.9 & 1.073 \\
\hline$T_{6-10}$ & 1.1 & 0.9 & 1.1 & 1.1 & 1.1 & 0.9 & 0.9 & 0.9001 \\
\hline$T_{4-12}$ & 0.9726 & 0.9729 & 1.0063 & 1.1 & 0.9553 & 0.9 & 0.9 & 0.9411 \\
\hline $\mathrm{T}_{28-27}$ & 0.9896 & 0.9746 & 0.998 & 1.0041 & 0.9644 & 0.9 & 0.9 & 0.9522 \\
\hline $\mathrm{Q}_{\mathrm{sc} 3}$ & 0.0 & 0.0 & 0.0 & 0.0 & 0.094958 & 0.0003 & 0.2993 & 0.0915 \\
\hline $\mathrm{Q}_{\mathrm{sc} 10}$ & 0.36 & 0.2362 & 0.36 & 0.0954 & 0.36 & 0.0005 & 0.2993 & 0.2824 \\
\hline $\mathrm{Q}_{\mathrm{sc24}}$ & 0.0949 & 10.056 & 0.1032 & 0.107 & 0.0994 & 0.0003 & 0.2993 & 0.0978 \\
\hline$P_{\text {loss }}(\mathrm{MW})$ & 4.7915 & 4.7392 & 4.8655 & 4.7282 & 4.7190 & 6.2775 & 5.0957 & 4.5983 \\
\hline ICA [31] & IWO [31] & $\begin{array}{l}\text { MICA-IWO } \\
{[31]}\end{array}$ & C-PSO [32] & Cl-PSO [32] & LDI-PSO [32] & B-DE [32] & R-DE [32] & SFLA [32] \\
\hline 4.6155 & 4.6287 & 4.5984 & 4.6801 & 4.6124 & 4.6124 & 4.6124 & 4.6675 & 4.6148 \\
\hline \multicolumn{9}{|l|}{ NMSFLA [32] } \\
\hline 4.6118 & & & & & & & & \\
\hline
\end{tabular}

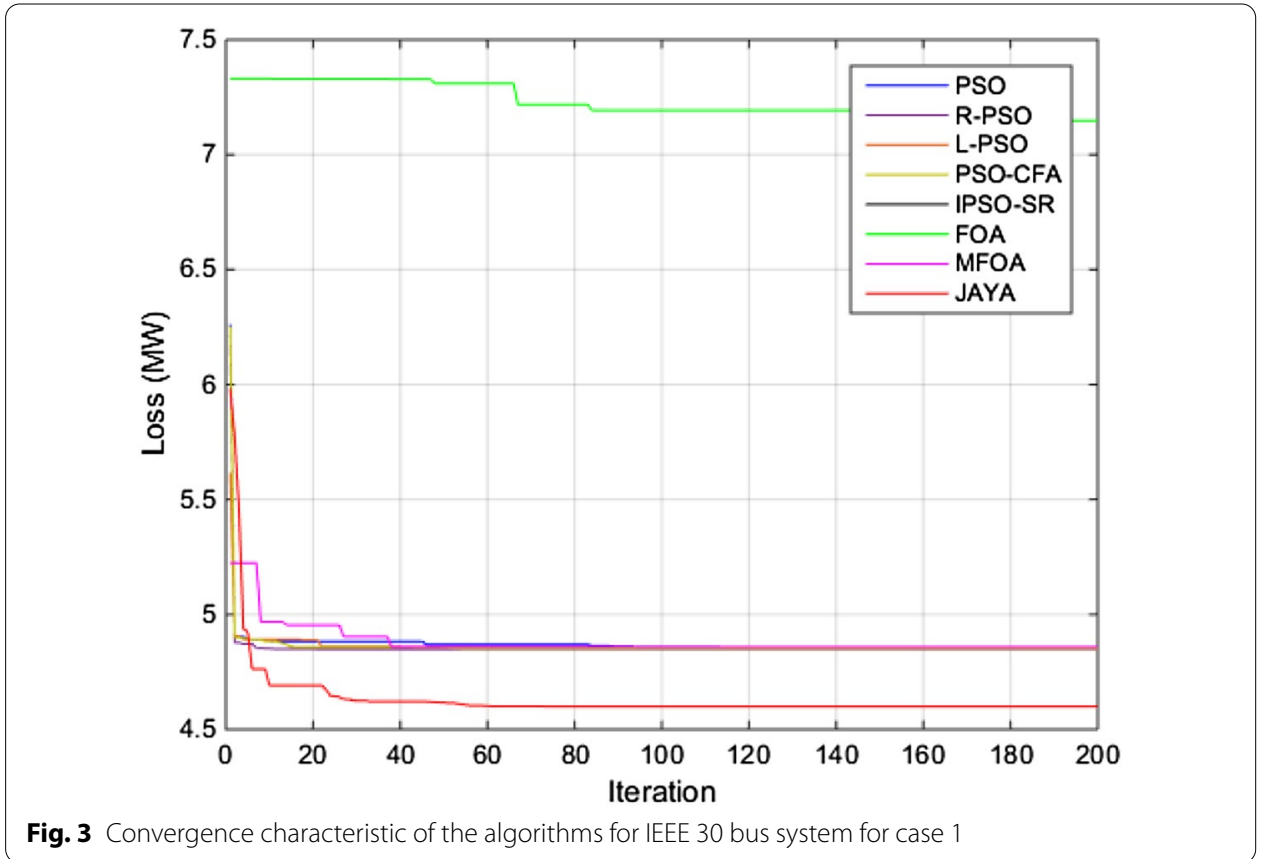

of the JAYA algorithm among all the reported algorithms in determining the best solution to the ORPD problem. It has reduced the power loss to a level of 12.227 MW, which is the maximum reduction as reported in the literature. It has high 


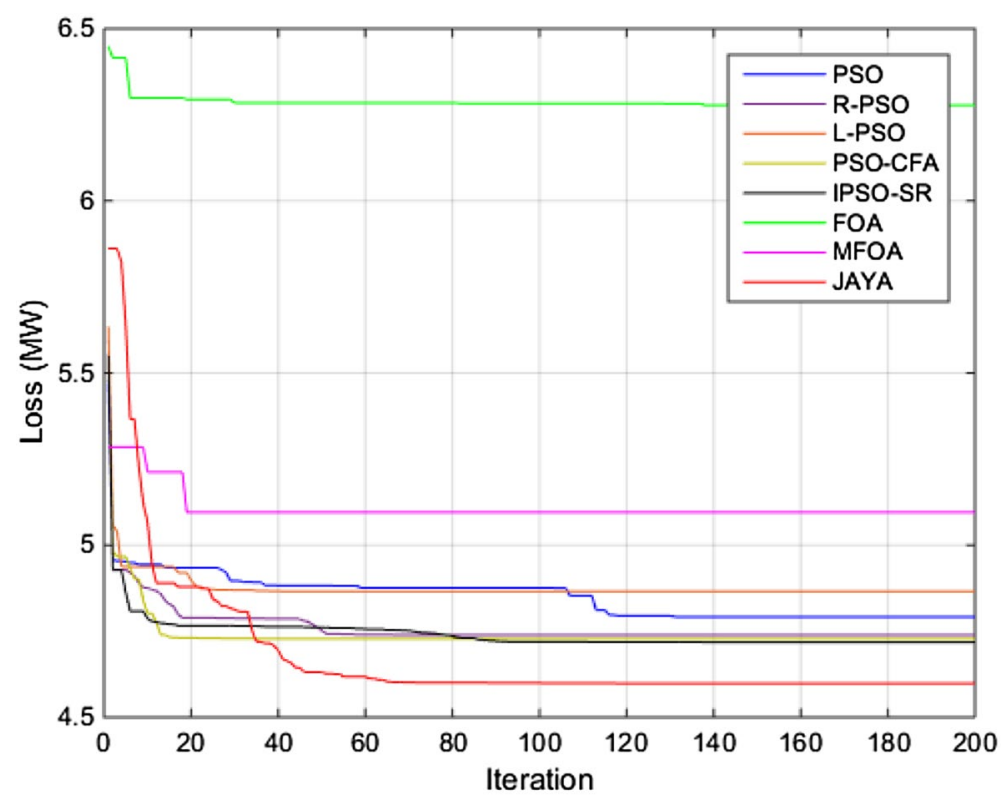

Fig. 4 Convergence characteristic of the algorithms for IEEE 30 bus system for case 2

Table 7 Statistical analysis for case 2 of IEEE 30 bus system

\begin{tabular}{llllll}
\hline Algorithm & Best (MW) & Worst (MW) & Mean (p.u.) & Standard deviation (SD) & \% of Power save \\
\hline C-PSO [31] & 4.68017 & 5.69149 & 5.14339 & $2.8854 \times 10^{-3}$ & 17.3114 \\
CI-PSO [31] & 4.61244 & 4.87635 & 4.64732 & $5.834 \times 10^{-4}$ & 18.5081 \\
LDI-PSO [31] & 4.61243 & 4.93822 & 4.62908 & $4.851 \times 10^{-4}$ & 18.5083 \\
B-DE [31] & 4.61243 & 4.61333 & 4.61281 & $2.6 \times 10^{-6}$ & 18.5083 \\
R-DE [31] & 4.66755 & 4.98274 & 4.75088 & $6.54 \times 10^{-4}$ & 17.5344 \\
SFLA [31] & 4.61483 & 4.97653 & 4.72213 & $9.973 \times 10^{-4}$ & 18.4659 \\
NMSFLA [31] & 4.61181 & 4.61749 & 4.61264 & $9.8 \times 10^{-6}$ & 18.5192 \\
ICA [31] & 4.6155 & 4.6624 & 4.6397 & $2.7613 \times 10^{-3}$ & 18.4541 \\
IWO [31] & 4.6287 & 4.9206 & 4.7813 & $3.1584 \times 10^{-2}$ & 18.2208 \\
MICA-IWO [31] & 4.5984 & 4.6009 & 4.5991 & $8.006 \times 10^{-6}$ & 18.7562 \\
PSO & 4.7915 & 4.9387 & 4.9053 & $9.08 \times 10^{-3}$ & 15.3445 \\
R-PSO & 4.7392 & 5.0006 & 4.8695 & $8.707 \times 10^{-3}$ & 16.2686 \\
L-PSO & 4.8655 & 5.0222 & 4.9496 & $5.1176 \times 10^{-3}$ & 14.0371 \\
PSO-CFA & 4.7282 & 4.9185 & 4.8334 & $6.668 \times 10^{-3}$ & 16.4629 \\
IPSO-SR & 4.719 & 4.9316 & 4.84455 & $6.668 \times 10^{-3}$ & 16.6254 \\
FOA & 6.2775 & 6.3832 & 6.3605 & $5.3887 \times 10^{-3}$ & -10.9099 \\
MFOA & 5.0957 & 5.1424 & 5.13425 & $1.724 \times 10^{-3}$ & 9.97 \\
JAYA & 4.5983 & 4.5986 & 4.5984 & $9.4281 \times 10^{-5}$ & 18.7579 \\
\hline
\end{tabular}

convergence rate and enormous capability of searching the optimal result to the objective function. 
Table 8 Frequency of convergence for IEEE 30 bus system case 2 in 50 trial runs

\begin{tabular}{lllllllll}
\hline Algorithms & $\mathbf{4 . 5 9 - 4 . 6 0}$ & $\mathbf{4 . 6 1 - 4 . 7 0}$ & $\mathbf{4 . 7 1 - 4 . 8 0}$ & $\mathbf{4 . 8 1 - 4 . 9 0}$ & $\mathbf{4 . 9 1 - 5 . 0}$ & $\mathbf{5 . 0 1 - 5 . 1 0}$ & $\mathbf{5 . 1 1 - 5 . 2 0}$ & $\mathbf{> 6 . 0 1}$ \\
\hline PSO & 0 & 0 & 1 & 30 & 19 & 0 & 0 & 0 \\
R-PSO & 0 & 0 & 11 & 33 & 6 & 0 & 0 & 0 \\
L-PSO & 0 & 0 & 3 & 25 & 22 & 0 & 0 & 0 \\
PSO-CFA & 0 & 0 & 18 & 27 & 5 & 0 & 0 & 0 \\
IPSO-SR & 0 & 0 & 4 & 29 & 17 & 0 & 0 & 0 \\
FOA & 0 & 0 & 0 & 0 & 0 & 0 & 0 & 50 \\
MFOA & 0 & 0 & 0 & 0 & 0 & 1 & 49 & 0 \\
JAYA & 50 & 0 & 0 & 0 & 0 & 0 & 0 & 0 \\
\hline
\end{tabular}

Table 9 Control variable limits (p.u.) for the test cases

\begin{tabular}{|c|c|c|c|c|c|c|}
\hline Case no & $V_{g}^{\min }$ & $V_{g}^{\max }$ & $V_{P Q}^{\min }$ & $V_{P Q}^{\max }$ & $T^{\min }$ & $T^{\max }$ \\
\hline \multicolumn{7}{|c|}{ Limits of voltages and tap-settings (p.u.) } \\
\hline 1 & 0.94 & 1.06 & 0.94 & 1.06 & 0.9 & 1.1 \\
\hline 2 & 0.9 & 1.1 & 0.94 & 1.06 & 0.9 & 1.1 \\
\hline Bus no & & 18 & & 25 & & 53 \\
\hline \multicolumn{7}{|c|}{ Limits of the reactive power sources (p.u.) for both the cases } \\
\hline$Q_{c}^{\min }$ & & 0 & & 0 & & 0 \\
\hline$Q_{c}^{\max }$ & & 0.1 & & 0.059 & & 0.063 \\
\hline
\end{tabular}

\section{IEEE 30 bus system}

The IEEE 30 bus system has six number of generators at buses 1, 2, 5, 8, 11 and 13 out of which bus number 1 is the slack bus. It has 41 transmission lines where four number of tap-changing transformers are situated at branches $6-9,6-10,4-12$ and 28-27. The VAR injection is done at buses 3,10 and 24. Two different case studies have been done for this test case depending upon the limits of the control variables. The ORPD problem is solved, and the optimal values of the control variables are determined using the different algorithms mentioned in the literature.

The case details along with the limits of the control variables are listed in Table 4. The simulation results of the algorithms for cases 1 and 2 are shown in Tables 5 and 6, and the convergence characteristic is shown in Figs. 3 and 4, respectively.

The results show that the minimum power loss has been observed for the case 2, and the JAYA algorithm has given better results compared to the other reported algorithm for all the cases. The convergence rate of JAYA algorithm has proved to be much faster and more accurate compared to the others in determining the power loss. The JAYA algorithm has obtained the best solution of $4.5983 \mathrm{MW}$ for the case 2 by saving the power to $18.7579 \%$, which is very impressive and is the highest recorded power saving in the ORPD problem for this test case under similar condition and constraint.

Table 7 shows the statistical analysis of the algorithms used in this paper for case 2 of the IEEE 30 bus system. The table compares the best (Best) and worst (Worst) values of the solutions of the ORPD problem along with the standard deviation (std.) and mean of the results for the different algorithms individually. The comparison of 
Table 10 Simulation results on IEEE 57 bus system using different algorithms for case 1

\begin{tabular}{|c|c|c|c|c|c|c|c|c|}
\hline $\begin{array}{l}\text { Control } \\
\text { variables } \\
\text { (p.u.) }\end{array}$ & PSO & R-PSO & L-PSO & PSO-CFA & IPSO-SR & FOA & MFOA & JAYA \\
\hline$V_{G 1}$ & 1.06 & 1.06 & 1.06 & 1.06 & 1.06 & 0.9704 & 1.06 & 1.06 \\
\hline$V_{\mathrm{G} 2}$ & 1.06 & 1.06 & 1.06 & 1.06 & 1.06 & 0.94 & 1.06 & 1.06 \\
\hline$V_{G 3}$ & 1.06 & 1.06 & 1.06 & 1.06 & 1.06 & 0.94 & 1.06 & 1.0495 \\
\hline$V_{G 6}$ & 1.06 & 1.06 & 1.0497 & 1.06 & 1.06 & 0.94 & 1.06 & 1.0436 \\
\hline$V_{G 8}$ & 1.06 & 1.06 & 1.06 & 1.06 & 1.06 & 0.94 & 1.06 & 1.06 \\
\hline$V_{G 9}$ & 1.06 & 1.06 & 1.06 & 1.06 & 1.06 & 0.94 & 1.06 & 1.0450 \\
\hline$V_{G 12}$ & 1.06 & 1.06 & 1.06 & 1.06 & 1.06 & 0.94 & 1.06 & 1.0411 \\
\hline $\mathrm{T}_{4-18}$ & 1.1 & 1.1 & 1.1 & 1.1 & 1.1 & 0.9 & 0.9 & 0.9 \\
\hline $\mathrm{T}_{4-18}$ & 1.1 & 1.1 & 1.1 & 1.1 & 1.1 & 0.9 & 0.9 & 0.9 \\
\hline$T_{21-20}$ & 1.1 & 1.1 & 1.1 & 1.1 & 1.1 & 0.9 & 0.9 & 0.9829 \\
\hline$T_{24-26}$ & 1.1 & 1.0822 & 1.0308 & 1.0273 & 1.1 & 0.9 & 0.9 & 0.9875 \\
\hline $\mathrm{T}_{7-29}$ & 1.1 & 1.1 & 1.1 & 1.046 & 1.1 & 0.9 & 0.9 & 0.9 \\
\hline$T_{34-32}$ & 0.9692 & 0.9693 & 1.1 & 1.1 & 1.1 & 0.9 & 0.9 & 0.9743 \\
\hline $\mathrm{T}_{11-41}$ & 1.1 & 1.1 & 1.1 & 1.1 & 1.1 & 0.9 & 0.9 & 0.9 \\
\hline$T_{15-45}$ & 0.995 & 1.0023 & 1.1 & 1.0042 & 0.9 & 0.9 & 0.9 & 0.9 \\
\hline $\mathrm{T}_{14-46}$ & 1.0091 & 1.0078 & 1.0518 & 1.0095 & 0.9164 & 0.9 & 0.9 & 0.9 \\
\hline $\mathrm{T}_{10-51}$ & 1.1 & 1.1 & 1.1 & 1.1 & 0.9345 & 0.9 & 0.9 & 0.9110 \\
\hline $\mathrm{T}_{13-49}$ & 0.9745 & 0.9778 & 1.0122 & 0.9795 & 0.9 & 0.9 & 0.9 & 0.9 \\
\hline$T_{11-43}$ & 1.1 & 1.1 & 1.1 & 1.1 & 0.9 & 0.9 & 0.9 & 0.9 \\
\hline $\mathrm{T}_{40-56}$ & 1.1 & 1.1 & 1.1 & 1.1 & 1.0733 & 0.9095 & 0.9 & 1.0156 \\
\hline$T_{39-57}$ & 1.1 & 1.1 & 1.1 & 1.1 & 1.0412 & 0.9 & 0.9 & 0.9838 \\
\hline$T_{9-55}$ & 1.1 & 1.1 & 1.1 & 1.1 & 1.1 & 0.9 & 0.9 & 0.9006 \\
\hline $\mathrm{Q}_{\mathrm{sc} 18}$ & 0.10 & 0.10 & 0.0138 & 0.094 & 0.10 & 0.0009 & 0 & 0.0999 \\
\hline $\mathrm{Q}_{\mathrm{sc} 25}$ & 0.059 & 0.059 & 0.059 & 0.059 & 0.059 & 0.007 & 0 & 0.059 \\
\hline $\mathrm{Q}_{\mathrm{sc53}}$ & 0.063 & 0.063 & 0.063 & 0.063 & 0.063 & 0.0015 & 0 & 0.063 \\
\hline$P_{\text {loss }}(\mathrm{MW})$ & 26.1507 & 26.1354 & 26.7281 & 26.1826 & 25.3875 & 31.6433 & 24.9314 & 23.4710 \\
\hline HSA [30] & SGA [30] & $\begin{array}{l}\text { DMSDE } \\
{[30]}\end{array}$ & DE [30] & CLPSO [30] & AGA [30] & CGA [30] & ICA [31] & IWO [31] \\
\hline 24.5612 & 25.03 & 24.266 & 25.0862 & 25.0684 & 24.4857 & 24.8853 & 24.4799 & 24.5939 \\
\hline $\begin{array}{l}\text { MICA-IWO } \\
\text { [31] }\end{array}$ & SOA [10] & PSO-w [10] & L-SaDE [10] & $\mathrm{ABC}[34]$ & MVMO [33] & DE [34] & JADE [34] & $\begin{array}{l}\text { JADE-vPS } \\
{[34]}\end{array}$ \\
\hline 24.25684 & 24.26548 & 24.27052 & 24.26739 & 24.1846 & 24.8512 & 24.8360 & 24.8493 & 24.8451 \\
\hline FA [20] & GWO [20] & SOA [20] & CSA [20] & ALO [20] & MFO [20] & & & \\
\hline 24.4587 & 24.7523 & 24.2677 & 24.2619 & 24.7621 & 24.2529 & & & \\
\hline
\end{tabular}

the results prove that the JAYA algorithm has obtained the best solution to the problem and is also the most consistent and robust as it has very impressive standard. compared to most of the other algorithms. It has the best solution and has been able to reduce the active power loss to almost $18.7579 \%$ (4.5983 MW), which is the maximum reduction compared to the others as reported in the literature.

In order to investigate how frequently the results from the different algorithms converge within different range of solutions, a comparison has been done for case 2 of IEEE 30 bus system. This is a comparison of the frequency of convergence and is shown in Table 8. The table shows the number of times each algorithm has produced the solution within a specified range when ORPD problem is run for 50 times each for every single algorithm that has been worked out in this paper. The results show 
Table 11 Simulation results on IEEE 57 bus system using different algorithms for case 2

\begin{tabular}{|c|c|c|c|c|c|c|c|c|}
\hline $\begin{array}{l}\text { Control } \\
\text { Variables } \\
\text { (p.u.) }\end{array}$ & PSO & R-PSO & L-PSO & PSO-CFA & IPSO-SR & FOA & MFOA & JAYA \\
\hline$V_{G 1}$ & 1.1 & 1.1 & 1.1 & 1.1 & 1.1 & 0.9127 & 0.9 & 1.1 \\
\hline$V_{G 2}$ & 1.1 & 1.1 & 1.1 & 1.1 & 1.1 & 0.9 & 0.9 & 1.0991 \\
\hline$V_{G 3}$ & 1.1 & 1.1 & 1.1 & 1.1 & 1.1 & 0.9 & 0.9 & 1.0888 \\
\hline$V_{G 6}$ & 1.1 & 1.1 & 1.1 & 1.1 & 1.1 & 0.9 & 0.9 & 1.0834 \\
\hline$V_{G 8}$ & 1.1 & 1.1 & 1.1 & 1.1 & 1.1 & 0.9 & 0.9 & 1.1 \\
\hline$V_{G 9}$ & 1.1 & 1.1 & 1.1 & 1.1 & 1.1 & 0.9 & 0.9 & 1.0848 \\
\hline$V_{G 12}$ & 1.1 & 1.1 & 1.1 & 1.1 & 1.1 & 0.9 & 0.9 & 1.0806 \\
\hline $\mathrm{T}_{4-18}$ & 1.1 & 1.1 & 1.1 & 1.1 & 1.1 & 0.9 & 0.9 & 0.9 \\
\hline $\mathrm{T}_{4-18}$ & 1.1 & 1.1 & 1.1 & 1.1 & 1.1 & 0.9 & 0.9 & 0.9 \\
\hline$T_{21-20}$ & 1.1 & 1.1 & 1.1 & 0.9918 & 1.1 & 0.9 & 0.9243 & 0.9824 \\
\hline $\mathrm{T}_{24-26}$ & 1.0036 & 1.1 & 1.015 & 0.9971 & 1.0642 & 0.9 & 0.9 & 0.9865 \\
\hline$T_{7-29}$ & 1.1 & 1.1 & 1.1 & 1.1 & 1.1 & 0.9 & 0.9 & 0.9 \\
\hline$T_{34-32}$ & 0.9671 & 1.1 & 0.9688 & 0.9662 & 1.1 & 1.1 & 0.9 & 0.9751 \\
\hline$T_{11-41}$ & 1.1 & 1.1 & 1.1 & 1.1 & 1.1 & 0.9 & 0.9 & 0.9 \\
\hline $\mathrm{T}_{15-45}$ & 1.1 & 1.0046 & 1.1 & 1.1 & 1.0133 & 0.9 & 0.9 & 0.9 \\
\hline $\mathrm{T}_{14-46}$ & 1.1 & 1.0095 & 1.1 & 1.1 & 1.0176 & 0.9 & 0.9 & 0.9 \\
\hline$T_{10-51}$ & 1.1 & 1.1 & 1.1 & 1.1 & 1.1 & 0.9 & 0.9 & 0.9101 \\
\hline $\mathrm{T}_{13-49}$ & 1.1 & 0.9823 & 1.0333 & 1.1 & 0.9895 & 0.9 & 0.9 & 0.9 \\
\hline $\mathrm{T}_{11-43}$ & 1.1 & 1.1 & 1.1 & 1.1 & 1.1 & 0.9 & 0.9 & 0.9 \\
\hline $\mathrm{T}_{40-56}$ & 1.1 & 1.1 & 1.1 & 1.027 & 1.1 & 0.9 & 0.9 & 1.0111 \\
\hline$T_{39-57}$ & 1.1 & 1.1 & 1.1 & 0.9829 & 1.1 & 0.9 & 0.9 & 0.9841 \\
\hline$T_{9-55}$ & 1.1 & 1.1 & 1.1 & 1.1 & 1.1 & 0.9 & 0.9 & 0.9002 \\
\hline $\mathrm{Q}_{\mathrm{sc18}}$ & 0.0 & 0.0 & 0.0 & 0.10 & 0.0616 & 0.0012 & 0.008 & 0.0976 \\
\hline $\mathrm{Q}_{\mathrm{sc} 25}$ & 0.059 & 0.059 & 0.059 & 0.059 & 0.059 & 0.0026 & 0.0059 & 0.059 \\
\hline $\mathrm{Q}_{\mathrm{sc} 53}$ & 0.063 & 0.063 & 0.063 & 0.063 & 0.063 & 0.0014 & 0.0059 & 0.063 \\
\hline$P_{\text {loss }}(M W)$ & 24.8254 & 24.2539 & 24.5676 & 24.5873 & 24.2012 & 33.5557 & 23.0158 & 21.5481 \\
\hline $\begin{array}{l}\text { ALC-PSO } \\
{[16]}\end{array}$ & $\mathrm{BBO}[16]$ & GSA [16] & $\begin{array}{l}\text { CPVEI } \\
\text { HBMO } \\
{[16]}\end{array}$ & HBMO [16] & OGSA [16] & BSO 1 [16] & BSO 2 [16] & BSO 3 [16] \\
\hline 23.39 & 24.544 & 24.439 & 22.78 & 23.24 & 23.43 & 24.5025 & 24.4856 & 24.4492 \\
\hline BSO 4 [16] & BSO 5 [16] & $\begin{array}{l}\text { SGA }\left(F_{f 1}\right) \\
{[35]}\end{array}$ & $\begin{array}{l}\text { SGA }\left(F_{f 2}\right) \\
{[35]}\end{array}$ & PSO [36] & ICA [36] & $\begin{array}{l}\text { PSO-ICA } \\
{[36]}\end{array}$ & $\begin{array}{l}\text { MOALO } \\
{[37]}\end{array}$ & DSA [38] \\
\hline 24.3744 & 24.6431 & 23.836 & 24.325 & 24.7742 & 24.1607 & 24.1386 & 26.593 & 23.35 \\
\hline BSO [16] & WCA [39] & $\begin{array}{l}\text { GBWCA } \\
{[39]}\end{array}$ & GSA [40] & CSA [40] & $\begin{array}{l}\text { MCBOA } \\
{[40]}\end{array}$ & $\mathrm{BA}[41]$ & FPA [41] & \\
\hline 24.3744 & 24.82 & 23.27 & 24.4922 & 24.2619 & 23.6943 & 24.9254 & 24.8419 & \\
\hline
\end{tabular}

the JAYA algorithm is undoubtedly the only one to produce all the result within the minimum range of 4.59-4.60 MW, and no other algorithm has obtained any solution within this range. Moreover, the MFOA technique is also quite consistent, as it has frequently obtained the solution within the range of 5.11-5.20 MW (49 times). However, the algorithm has failed to optimize the function to lower limits. Thus, the results prove that the JAYA algorithm has the capability of converging most frequently to the minimum solution. 


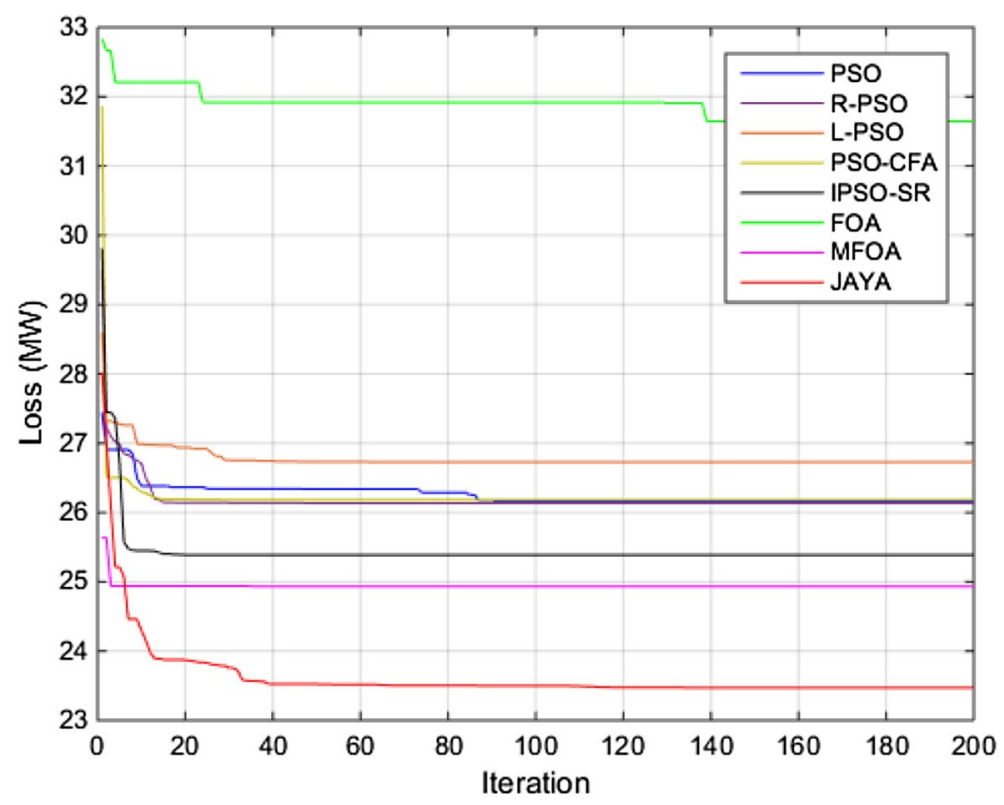

Fig. 5 Convergence characteristic of the algorithms for IEEE 57 bus system for case 1

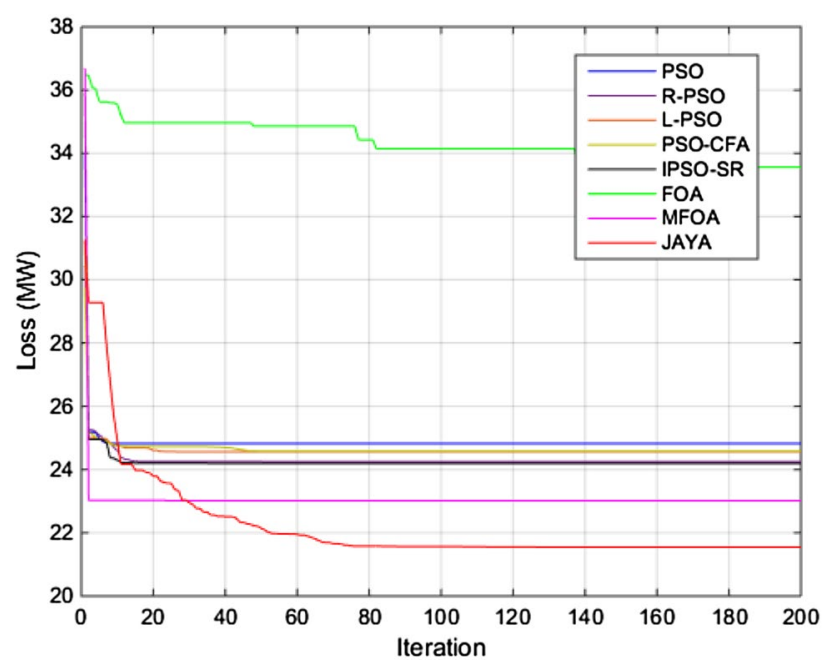

Fig. 6 Convergence characteristic of the algorithms for IEEE 57 bus system for case 2

\section{IEEE 57 bus system}

The IEEE 57 bus system has seven generators situated at the buses 1, 2, 3, 6, 8, 9 and 12 where bus number 1 is the slack bus. It has tap-changing transformers connected to the 15 out of the total 80 branches. The transformers are connected between 21-20, 24-26, 7-29, 34-32, 11-41, 15-45, 14-46, 10-51, 13-49, 11-43, 40-56, 39-57 and 9-55. The reactive powers sources are injected at the buses 18, 25 and 53. Here, two case studies have been done to solve the ORPD problem and determine the optimal solution for each case individually. The upper and lower limits of the control variables are given in Table 9. The simulation results for both case 1 and case 2 using 
Table 12 Control variable limits (p.u.) for the test cases

\begin{tabular}{|c|c|c|c|c|c|c|c|c|}
\hline Case no & $V_{g}^{\min }$ & $V_{g}^{\max }$ & & $V_{P Q}^{\min }$ & & $V_{P Q}^{\max }$ & $T^{\min }$ & $T^{\max }$ \\
\hline \multicolumn{9}{|c|}{ Limits of voltages and tap-settings (p.u.) } \\
\hline 1 & 0.94 & 1.06 & & 0.94 & & 1.06 & 0.9 & 1.1 \\
\hline 2 & 0.9 & 1.1 & & 0.94 & & 1.06 & 0.9 & 1.1 \\
\hline Bus no & 5 & 34 & 37 & & 44 & 45 & 46 & 48 \\
\hline \multicolumn{9}{|c|}{ Limits of the reactive power sources (p.u.) for both the cases } \\
\hline$Q_{c}^{\min }$ & -0.4 & 0 & -0.25 & & 0 & 0 & 0 & 0 \\
\hline$Q_{c}^{\max }$ & 0 & 0.14 & 0 & & 0.1 & 0.1 & 0.1 & 0.15 \\
\hline Bus no & 74 & 79 & 82 & & 83 & 105 & 107 & 110 \\
\hline$Q_{C}^{\min }$ & 0 & 0 & 0 & & 0 & 0 & 0 & 0 \\
\hline$Q_{c}^{\max }$ & 0.12 & 0.2 & 0.2 & & 0.1 & 0.2 & 0.06 & 0.06 \\
\hline
\end{tabular}

all the algorithms are represented in Tables 10 and 11, and the comparative convergence characteristics are shown in Figs. 5 and 6, respectively.

The results show that the power loss for case 2 has been minimized the most by JAYA algorithm, to almost $22.67 \%$ (21.5481 MW). It has obtained the best solution due to its high capability in searching for the best solution in every iteration and avoiding the risk of being stuck in to the local optima unlike the other algorithms in caparison. The comparison of the results establish the superiority of the proposed algorithm in determining the optimal results for the problem. Thus, it is more consistent, accurate and most effective in minimizing the loss in the problem compared to the other reported algorithms.

\section{IEEE 118 bus system}

In order to test the effectiveness of the JAYA algorithm in a larger scale, this ORPD problem has been solved on the IEEE 118 bus system. This test system has 54 generators, 14 shunt compensators, 9 tap-changing transformers and 186 transmission lines. The limits of the control variables are given in Table 12. Two different cases have been considered for solving the ORPD problem where the upper and lower limits of the generator voltages are chosen differently. This has been done depending upon the different cases considered by the researchers in recent past for solving the ORPD problem the same bus system. Thus, the different test cases are considered here in order to investigate the capability of the proposed JAYA algorithm in solving the ORPD problem for both the possible conditions and compare the results with those of the other reported in the literature. Thus, the algorithms are tested and the simulation results along with the comparative convergence characteristic are shown in Tables 13, 14 and Figs. 7 and 8 for both the cases, respectively.

The tables show the optimal values of the control variables for which the best solution of the power loss has been obtained. The comparison of the results show that the proposed JAYA algorithm is the best among the other reported algorithms in determining the better solution to the ORPD problem for both the cases. The convergence characteristics does reflect the slow convergence of the JAYA algorithm compared to others for this particular higher order system, but the efficiency 
Table 13 Simulation results on IEEE 118 bus system using different algorithms for case 1

\begin{tabular}{|c|c|c|c|c|c|c|c|c|}
\hline $\begin{array}{l}\text { Control } \\
\text { variables } \\
\text { (p.u.) }\end{array}$ & PSO & R-PSO & L-PSO & PSO-CFA & IPSO-SR & FOA & MFOA & JAYA \\
\hline$V_{G 1}$ & 1.06 & 1.06 & 1.06 & 1.06 & 1.06 & 0.94 & 1.06 & 1.0434 \\
\hline$V_{G 4}$ & 1.06 & 1.06 & 1.06 & 1.06 & 1.06 & 0.94 & 1.06 & 1.06 \\
\hline$V_{G 6}$ & 1.06 & 1.06 & 1.06 & 1.06 & 1.06 & 0.94 & 1.06 & 1.0545 \\
\hline$V_{G 8}$ & 1.06 & 1.06 & 1.06 & 1.06 & 1.06 & 1.06 & 1.06 & 1.06 \\
\hline$V_{G 10}$ & 1.06 & 1.06 & 1.06 & 1.06 & 1.06 & 1.06 & 1.06 & 1.06 \\
\hline$V_{G 12}$ & 1.06 & 1.06 & 1.06 & 1.06 & 1.06 & 0.94 & 1.06 & 1.0516 \\
\hline$V_{G 15}$ & 1.06 & 1.06 & 1.06 & 1.06 & 1.06 & 0.94 & 1.06 & 1.0512 \\
\hline$V_{G 18}$ & 1.06 & 1.06 & 1.06 & 1.06 & 1.06 & 0.94 & 1.06 & 1.0535 \\
\hline$V_{G 19}$ & 1.06 & 1.06 & 1.06 & 1.06 & 1.06 & 0.94 & 1.06 & 1.0503 \\
\hline$V_{G 24}$ & 1.06 & 1.06 & 1.06 & 1.06 & 1.06 & 0.94 & 1.06 & 1.0528 \\
\hline$V_{G 25}$ & 1.06 & 1.06 & 1.06 & 1.06 & 1.06 & 0.94 & 1.06 & 1.06 \\
\hline$V_{G 26}$ & 1.06 & 1.06 & 1.06 & 1.06 & 1.06 & 1.06 & 1.06 & 1.06 \\
\hline$V_{G 27}$ & 1.06 & 1.06 & 1.06 & 1.06 & 1.06 & 0.94 & 1.06 & 1.047 \\
\hline$V_{G 31}$ & 1.06 & 1.06 & 1.06 & 1.06 & 1.06 & 0.94 & 1.06 & 1.0436 \\
\hline$V_{G 32}$ & 1.06 & 1.06 & 1.06 & 1.06 & 1.06 & 0.94 & 1.06 & 1.0458 \\
\hline$V_{G 34}$ & 1.06 & 1.06 & 1.06 & 1.06 & 1.06 & 0.94 & 1.06 & 1.06 \\
\hline$V_{G 36}$ & 1.06 & 1.06 & 1.06 & 1.06 & 1.06 & 0.94 & 1.06 & 1.0584 \\
\hline$V_{G 40}$ & 1.06 & 1.06 & 1.06 & 1.06 & 1.06 & 0.94 & 1.06 & 1.0391 \\
\hline$V_{G 42}$ & 1.06 & 1.06 & 1.06 & 1.06 & 1.06 & 0.94 & 1.06 & 1.0397 \\
\hline$V_{G 46}$ & 1.06 & 1.06 & 1.06 & 1.06 & 1.06 & 0.94 & 1.06 & 1.0471 \\
\hline$V_{G 49}$ & 1.06 & 1.06 & 1.06 & 1.06 & 1.06 & 0.94 & 1.06 & 1.06 \\
\hline$V_{G 54}$ & 1.06 & 1.06 & 1.06 & 1.06 & 1.06 & 0.94 & 1.06 & 1.0392 \\
\hline$V_{G 55}$ & 1.06 & 1.06 & 1.06 & 1.06 & 1.06 & 0.94 & 1.06 & 1.0383 \\
\hline$V_{G 56}$ & 1.06 & 1.06 & 1.06 & 1.06 & 1.06 & 0.94 & 1.06 & 1.0385 \\
\hline$V_{G 59}$ & 1.06 & 1.06 & 1.06 & 1.06 & 1.06 & 0.94 & 1.06 & 1.06 \\
\hline$V_{G 61}$ & 1.06 & 1.06 & 1.06 & 1.06 & 1.06 & 0.94 & 1.06 & 1.06 \\
\hline$V_{G 62}$ & 1.06 & 1.06 & 1.06 & 1.06 & 1.06 & 0.94 & 1.06 & 1.0561 \\
\hline$V_{G 65}$ & 1.06 & 1.06 & 1.06 & 1.06 & 1.06 & 0.94 & 1.06 & 1.06 \\
\hline$V_{G 66}$ & 1.06 & 1.06 & 1.06 & 1.06 & 1.06 & 0.94 & 1.06 & 1.06 \\
\hline$V_{G 69}$ & 1.06 & 1.06 & 1.06 & 1.06 & 1.06 & 0.94 & 1.06 & 1.06 \\
\hline$V_{G 70}$ & 1.06 & 1.06 & 1.06 & 1.06 & 1.06 & 0.94 & 1.06 & 1.0378 \\
\hline$V_{G 72}$ & 1.06 & 1.06 & 1.06 & 1.06 & 1.06 & 0.94 & 1.06 & 1.0424 \\
\hline$V_{G 73}$ & 1.06 & 1.06 & 1.06 & 1.06 & 1.06 & 0.94 & 1.06 & 1.0375 \\
\hline$V_{G 74}$ & 1.06 & 1.06 & 1.06 & 1.06 & 1.06 & 0.94 & 1.06 & 1.0276 \\
\hline$V_{G 76}$ & 1.06 & 1.06 & 1.06 & 1.06 & 1.06 & 0.94 & 1.06 & 1.0252 \\
\hline$V_{G 77}$ & 1.06 & 1.06 & 1.06 & 1.06 & 1.06 & 0.94 & 1.06 & 1.0474 \\
\hline$V_{G 80}$ & 1.06 & 1.06 & 1.06 & 1.06 & 1.06 & 0.94 & 1.06 & 1.06 \\
\hline$V_{G 85}$ & 1.06 & 1.06 & 1.06 & 1.06 & 1.06 & 0.94 & 1.06 & 1.06 \\
\hline$V_{G 87}$ & 1.06 & 1.06 & 1.06 & 1.06 & 1.06 & 0.94 & 1.06 & 1.0593 \\
\hline$V_{G 89}$ & 1.06 & 1.06 & 1.06 & 1.06 & 1.06 & 0.94 & 1.06 & 1.06 \\
\hline$V_{G 90}$ & 1.06 & 1.06 & 1.06 & 1.06 & 1.06 & 0.94 & 1.06 & 1.0438 \\
\hline$V_{G 91}$ & 1.06 & 1.06 & 1.06 & 1.06 & 1.06 & 0.94 & 1.06 & 1.0489 \\
\hline$V_{G 92}$ & 1.06 & 1.06 & 1.06 & 1.06 & 1.06 & 0.94 & 1.06 & 1.06 \\
\hline$V_{G 99}$ & 1.06 & 1.06 & 1.06 & 1.06 & 1.06 & 0.94 & 1.06 & 1.0552 \\
\hline$V_{G 100}$ & 1.06 & 1.06 & 1.06 & 1.06 & 1.06 & 0.94 & 1.06 & 1.06 \\
\hline$V_{\mathrm{G} 103}$ & 1.06 & 1.06 & 1.06 & 1.06 & 1.06 & 0.94 & 1.06 & 1.0517 \\
\hline$V_{G 104}$ & 1.06 & 1.06 & 1.06 & 1.06 & 1.06 & 0.94 & 1.06 & 1.0431 \\
\hline$V_{G 105}$ & 1.06 & 1.06 & 1.06 & 1.06 & 1.06 & 0.94 & 1.06 & 1.0392 \\
\hline
\end{tabular}


Table 13 (continued)

\begin{tabular}{|c|c|c|c|c|c|c|c|c|}
\hline $\begin{array}{l}\text { Control } \\
\text { variables } \\
\text { (p.u.) }\end{array}$ & PSO & R-PSO & L-PSO & PSO-CFA & IPSO-SR & FOA & MFOA & JAYA \\
\hline$V_{G 107}$ & 1.06 & 1.06 & 1.06 & 1.06 & 1.06 & 0.94 & 1.06 & 1.0261 \\
\hline$V_{G 110}$ & 1.06 & 1.06 & 1.06 & 1.06 & 1.06 & 0.94 & 1.06 & 1.0355 \\
\hline$V_{G 111}$ & 1.06 & 1.06 & 1.06 & 1.06 & 1.06 & 0.94 & 1.06 & 1.0434 \\
\hline$V_{G 112}$ & 1.06 & 1.06 & 1.06 & 1.06 & 1.06 & 0.94 & 1.06 & 1.0199 \\
\hline$V_{G 113}$ & 1.06 & 1.06 & 1.06 & 1.06 & 1.06 & 0.94 & 1.06 & 1.06 \\
\hline$V_{G 116}$ & 1.06 & 1.06 & 1.06 & 1.06 & 1.06 & 0.94 & 1.06 & 1.06 \\
\hline $\mathrm{T}_{5-8}$ & 0.9878 & 0.9877 & 0.9877 & 0.9878 & 0.9879 & 1.1 & 0.9 & 0.9904 \\
\hline $\mathrm{T}_{25-26}$ & 1.1 & 1.1 & 1.1 & 1.1 & 1.1 & 1.0716 & 0.9 & 1.1 \\
\hline $\mathrm{T}_{17-30}$ & 0.9946 & 0.9813 & 1.1 & 1.1 & 0.9945 & 0.9 & 0.9 & 0.9862 \\
\hline$T_{37-38}$ & 1.1 & 0.9787 & 0.9951 & 1.1 & 1.1 & 1.1 & 0.9 & 0.9822 \\
\hline$T_{59-63}$ & 1.1 & 1.1 & 1.1 & 0.9814 & 1.1 & 0.9 & 0.9 & 0.9818 \\
\hline $\mathrm{T}_{61-64}$ & 1.1 & 1.1 & 1.1 & 1.0021 & 1.1 & 0.9 & 0.9 & 1.0031 \\
\hline$T_{65-66}$ & 1.1 & 1.1 & 1.1 & 1.1 & 1.1 & 0.9 & 0.9 & 0.9668 \\
\hline $\mathrm{T}_{68-69}$ & 1.1 & 0.9227 & 0.9 & 1.1 & 1.1 & 0.9 & 0.9 & 0.9536 \\
\hline $\mathrm{T}_{80-81}$ & 1.1 & 1.1 & 1.1 & 0.9768 & 0.9771 & 0.9 & 0.9 & 0.991 \\
\hline $\mathrm{Q}_{\mathrm{sc5}}$ & 0.0 & 0.0 & 0.0 & 0.0 & 0.0 & 0.0 & 0.0 & 0.0000 \\
\hline $\mathrm{Q}_{\mathrm{sc} 34}$ & 0.0 & 0.0 & 0.0 & 0.0 & 0.0 & 0.0008 & 0.0557 & 0.1328 \\
\hline $\mathrm{Q}_{\text {sc37 }}$ & 0.0 & 0.0 & 0.0 & 0.0 & 0.0 & 0.0 & 0.0 & -0.0003 \\
\hline $\mathrm{Q}_{544}$ & 0.0 & 0.0 & 0.0 & 0.0 & 0.0 & 0.0011 & 0.0557 & 0.0930 \\
\hline $\mathrm{Q}_{\mathrm{sc45}}$ & 0.0 & 0.0 & 0.0 & 0.0 & 0.0 & 0.0015 & 0.0557 & 0.1000 \\
\hline $\mathrm{Q}_{\mathrm{sc46}}$ & 0.0 & 0.0 & 0.0 & 0.0 & 0.0 & 0.0009 & 0.0557 & 0.0972 \\
\hline $\mathrm{Q}_{\mathrm{sc48}}$ & 0.0 & 0.0 & 0.0 & 0.0 & 0.0 & 0.0016 & 0.0557 & 0.0760 \\
\hline $\mathrm{Q}_{\mathrm{sc74}}$ & 0.0 & 0.0 & 0.0 & 0.0 & 0.0 & 0.0015 & 0.0557 & 0.1199 \\
\hline $\mathrm{Q}_{\text {sc79 }}$ & 0.0 & 0.0 & 0.0 & 0.0 & 0.0 & 0.0011 & 0.0557 & 0.2000 \\
\hline $\mathrm{Q}_{\mathrm{sc} 82}$ & 0.0 & 0.0 & 0.0 & 0.0 & 0.0 & 0.0008 & 0.0557 & 0.2000 \\
\hline $\mathrm{Q}_{\mathrm{sc83}}$ & 0.0 & 0.0 & 0.0 & 0.0 & 0.0 & 0.0008 & 0.0557 & 0.1000 \\
\hline $\mathrm{Q}_{\mathrm{sc} 105}$ & 0.0 & 0.0 & 0.0 & 0.0 & 0.0 & 0.0005 & 0.0557 & 0.1841 \\
\hline $\mathrm{Q}_{\mathrm{sc} 107}$ & 0.0 & 0.0 & 0.0 & 0.0 & 0.0 & 0.0022 & 0.0557 & 0.0151 \\
\hline $\mathrm{Q}_{\mathrm{sC} 110}$ & 0.06 & 0.06 & 0.0 & 0.06 & 0.06 & 0.0027 & 0.0557 & 0.0057 \\
\hline$P_{\text {loss }}(\mathrm{MW})$ & 120.7712 & 118.8887 & 120.4271 & 119.6773 & 119.8839 & 147.4177 & 116.851 & 113.9979 \\
\hline $\mathrm{ACO}_{\mathrm{R}}[25]$ & $\begin{array}{l}\text { DE/ } \\
\text { best/2/ } \\
\text { bin [5] }\end{array}$ & $A B C[25]$ & LCA [25] & CSS [25] & BRCFF [25] & $\begin{array}{l}\text { BB-BC } \\
{[25]}\end{array}$ & TLA [25] & MTLA [25] \\
\hline 122.9456 & 118.4267 & 117.9922 & 120.0662 & 119.1621 & 116.5817 & 122.1314 & 116.0682 & 114.2213 \\
\hline $\begin{array}{l}\text { DMSDE } \\
\text { [30] }\end{array}$ & $\begin{array}{l}\text { PSO-w } \\
{[30]}\end{array}$ & AGA [30] & ICA [31] & IWO [31] & $\begin{array}{l}\text { MICA-IWO } \\
\text { [31] }\end{array}$ & CGA [10] & $\begin{array}{l}\text { CLPSO } \\
{[10]}\end{array}$ & L-SaDE [10] \\
\hline 115.37 & 115.8328 & 123.9636 & 118.3219 & 137.2954 & 114.0457 & 139.4149 & 123.1522 & 116.9057 \\
\hline SOA [10] & $\begin{array}{l}\text { MVMO } \\
{[34]}\end{array}$ & DE [34] & JADE [34] & $\begin{array}{l}\text { JADE-vPS } \\
{[34]}\end{array}$ & RGA [42] & $\begin{array}{l}\text { CMAES } \\
{[42]}\end{array}$ & $\begin{array}{l}\text { MOPSO } \\
{[42]}\end{array}$ & NSGA-II [42] \\
\hline 114.95013 & 115.7932 & 125.0250 & 119.1614 & 119.2006 & 122.1400 & 119.2750 & 119.5813 & 119.5799 \\
\hline $\begin{array}{l}\text { MNSGA-II } \\
{[42]}\end{array}$ & $\begin{array}{l}\text { L-SACP-DE } \\
{[43]}\end{array}$ & $\begin{array}{l}\text { HICA-PSO } \\
{[36]}\end{array}$ & ERWO [17] & & & & & \\
\hline 119.2790 & 141.8 & 127.82 & 116.44 & & & & & \\
\hline
\end{tabular}

of the algorithm ultimately enables it to determine the optimal solution which turns out to be the best result obtained among any other algorithms in comparison. The proposed algorithm has reduced the power loss to a value of 105.4821 MW for 
Table 14 Simulation results on IEEE 118 bus system using different algorithms for case 2

\begin{tabular}{|c|c|c|c|c|c|c|c|c|}
\hline $\begin{array}{l}\text { Control } \\
\text { variables } \\
\text { (p.u.) }\end{array}$ & PSO & R-PSO & L-PSO & PSO-CFA & IPSO-SR & FOA & MFOA & JAYA \\
\hline$V_{G 1}$ & 1.1 & 1.1 & 1.1 & 1.1 & 1.1 & 0.9 & 0.9 & 1.0801 \\
\hline$V_{G 4}$ & 1.1 & 1.1 & 1.1 & 1.1 & 1.1 & 0.9 & 0.9 & 1.1 \\
\hline$V_{G 6}$ & 1.1 & 1.1 & 1.1 & 1.1 & 1.1 & 0.9 & 0.9 & 1.0932 \\
\hline$V_{G 8}$ & 1.1 & 1.1 & 1.1 & 1.1 & 1.1 & 0.9 & 0.9 & 1.1 \\
\hline$V_{G 10}$ & 1.1 & 1.1 & 1.1 & 1.1 & 1.1 & 0.9 & 0.9 & 1.1 \\
\hline$V_{G 12}$ & 1.1 & 1.1 & 1.1 & 1.1 & 1.1 & 0.9 & 0.9 & 1.0896 \\
\hline$V_{G 15}$ & 1.1 & 1.1 & 1.1 & 1.1 & 1.1 & 0.9 & 0.9 & 1.0882 \\
\hline$V_{G 18}$ & 1.1 & 1.1 & 1.1 & 1.1 & 1.1 & 0.9 & 0.9 & 1.0886 \\
\hline$V_{G 19}$ & 1.1 & 1.1 & 1.1 & 1.1 & 1.1 & 0.9 & 0.9 & 1.0869 \\
\hline$V_{G 24}$ & 1.1 & 1.1 & 1.1 & 1.1 & 1.1 & 0.9 & 0.9 & 1.0912 \\
\hline$V_{G 25}$ & 1.1 & 1.1 & 1.1 & 1.1 & 1.1 & 0.9 & 0.9 & 1.1 \\
\hline$V_{G 26}$ & 1.1 & 1.1 & 1.1 & 1.1 & 1.1 & 0.9 & 0.9 & 1.1 \\
\hline$V_{G 27}$ & 1.1 & 1.1 & 1.1 & 1.1 & 1.1 & 0.9 & 0.9 & 1.0812 \\
\hline$V_{G 31}$ & 1.1 & 1.1 & 1.1 & 1.1 & 1.1 & 0.9 & 0.9 & 1.0755 \\
\hline$V_{G 32}$ & 1.1 & 1.1 & 1.1 & 1.1 & 1.1 & 0.9 & 0.9 & 1.0813 \\
\hline$V_{G 34}$ & 1.1 & 1.1 & 1.1 & 1.1 & 1.1 & 0.9 & 0.9 & 1.0989 \\
\hline$V_{G 36}$ & 1.1 & 1.1 & 1.1 & 1.1 & 1.1 & 0.9 & 0.9 & 1.096 \\
\hline$V_{G 40}$ & 1.1 & 1.1 & 1.1 & 1.1 & 1.1 & 0.9 & 0.9 & 1.0784 \\
\hline$V_{G 42}$ & 1.1 & 1.1 & 1.1 & 1.1 & 1.1 & 0.9437 & 0.9 & 1.078 \\
\hline$V_{G 46}$ & 1.1 & 1.1 & 1.1 & 1.1 & 1.1 & 0.9 & 0.9 & 1.0855 \\
\hline$V_{G 49}$ & 1.1 & 1.1 & 1.1 & 1.1 & 1.1 & 0.9 & 0.9 & 1.0977 \\
\hline$V_{G 54}$ & 1.1 & 1.1 & 1.1 & 1.1 & 1.1 & 0.9 & 0.9 & 1.0771 \\
\hline$V_{G 55}$ & 1.1 & 1.1 & 1.1 & 1.1 & 1.1 & 0.9 & 0.9 & 1.0756 \\
\hline$V_{G 56}$ & 1.1 & 1.1 & 1.1 & 1.1 & 1.1 & 0.9 & 0.9 & 1.0765 \\
\hline$V_{G 59}$ & 1.1 & 1.1 & 1.1 & 1.1 & 1.1 & 0.9 & 0.9 & 1.0994 \\
\hline$V_{G 61}$ & 1.1 & 1.1 & 1.1 & 1.1 & 1.1 & 0.9 & 0.9 & 1.0994 \\
\hline$V_{G 62}$ & 1.1 & 1.1 & 1.1 & 1.1 & 1.1 & 0.9 & 0.9 & 1.0956 \\
\hline$V_{G 65}$ & 1.1 & 1.1 & 1.1 & 1.1 & 1.1 & 0.9 & 0.9 & 1.1 \\
\hline$V_{G 66}$ & 1.1 & 1.1 & 1.1 & 1.1 & 1.1 & 0.9 & 0.9 & 1.1 \\
\hline$V_{G 69}$ & 1.1 & 1.1 & 1.1 & 1.1 & 1.1 & 0.956 & 0.9 & 1.0999 \\
\hline$V_{G 70}$ & 1.1 & 1.1 & 1.1 & 1.1 & 1.1 & 0.9 & 0.9 & 1.0776 \\
\hline$V_{G 72}$ & 1.1 & 1.1 & 1.1 & 1.1 & 1.1 & 0.9 & 0.9 & 1.081 \\
\hline$V_{G 73}$ & 1.1 & 1.1 & 1.1 & 1.1 & 1.1 & 0.9 & 0.9 & 1.0769 \\
\hline$V_{G 74}$ & 1.1 & 1.1 & 1.1 & 1.1 & 1.1 & 0.9 & 0.9 & 1.0669 \\
\hline$V_{G 76}$ & 1.1 & 1.1 & 1.1 & 1.1 & 1.1 & 0.9 & 0.9 & 1.0673 \\
\hline$V_{G 77}$ & 1.1 & 1.1 & 1.1 & 1.1 & 1.1 & 0.9 & 0.9 & 1.0867 \\
\hline$V_{G 80}$ & 1.1 & 1.1 & 1.1 & 1.1 & 1.1 & 0.9 & 0.9 & 1.0994 \\
\hline$V_{G 85}$ & 1.1 & 1.1 & 1.1 & 1.1 & 1.1 & 0.9 & 0.9 & 1.0995 \\
\hline$V_{G 87}$ & 1.1 & 1.1 & 1.1 & 1.1 & 1.1 & 0.9 & 0.9 & 1.1 \\
\hline$V_{G 89}$ & 1.1 & 1.1 & 1.1 & 1.1 & 1.1 & 0.9 & 0.9 & 1.1 \\
\hline$V_{G 90}$ & 1.1 & 1.1 & 1.1 & 1.1 & 1.1 & 0.9 & 0.9 & 1.0854 \\
\hline$V_{G 91}$ & 1.1 & 1.1 & 1.1 & 1.1 & 1.1 & 0.9 & 0.9 & 1.0895 \\
\hline$V_{G 92}$ & 1.1 & 1.1 & 1.1 & 1.1 & 1.1 & 0.9 & 0.9 & 1.1 \\
\hline$V_{G 99}$ & 1.1 & 1.1 & 1.1 & 1.1 & 1.1 & 0.9 & 0.9 & 1.0969 \\
\hline$V_{G 100}$ & 1.1 & 1.1 & 1.1 & 1.1 & 1.1 & 0.9 & 0.9 & 1.1 \\
\hline$V_{G 103}$ & 1.1 & 1.1 & 1.1 & 1.1 & 1.1 & 0.9 & 0.9 & 1.0918 \\
\hline$V_{G 104}$ & 1.1 & 1.1 & 1.1 & 1.1 & 1.1 & 0.9 & 0.9 & 1.083 \\
\hline$V_{G 105}$ & 1.1 & 1.1 & 1.1 & 1.1 & 1.1 & 0.9 & 0.9 & 1.077 \\
\hline
\end{tabular}


Table 14 (continued)

\begin{tabular}{|c|c|c|c|c|c|c|c|c|}
\hline $\begin{array}{l}\text { Control } \\
\text { variables } \\
\text { (p.u.) }\end{array}$ & PSO & R-PSO & L-PSO & PSO-CFA & IPSO-SR & FOA & MFOA & JAYA \\
\hline$V_{G 107}$ & 1.1 & 1.1 & 1.1 & 1.1 & 1.1 & 0.9 & 0.9 & 1.0669 \\
\hline$V_{G 110}$ & 1.1 & 1.1 & 1.1 & 1.1 & 1.1 & 0.9 & 0.9 & 1.0704 \\
\hline$V_{G 111}$ & 1.1 & 1.1 & 1.1 & 1.1 & 1.1 & 0.9 & 0.9 & 1.0774 \\
\hline$V_{G 112}$ & 1.1 & 1.1 & 1.1 & 1.1 & 1.1 & 0.9 & 0.9 & 1.0549 \\
\hline$V_{G 113}$ & 1.1 & 1.1 & 1.1 & 1.1 & 1.1 & 0.9 & 0.9 & 1.0968 \\
\hline$V_{G 116}$ & 1.1 & 1.1 & 1.1 & 1.1 & 1.1 & 0.9 & 0.9 & 1.0999 \\
\hline$T_{5-8}$ & 0.9905 & 1.1 & 1.1 & 1.1 & 1.1 & 0.9 & 0.9 & 0.9847 \\
\hline $\mathrm{T}_{25-26}$ & 1.1 & 1.1 & 1.1 & 1.1 & 1.1 & 0.922 & 0.9 & 1.0967 \\
\hline $\mathrm{T}_{17-30}$ & 1.1 & 1.1 & 1.1 & 1.1 & 1.1 & 0.9 & 0.9 & 0.9964 \\
\hline$T_{37-38}$ & 1.1 & 1.1 & 1.1 & 1.1 & 0.9942 & 0.9 & 0.9 & 0.983 \\
\hline$T_{59-63}$ & 1.1 & 0.982 & 0.9820 & 0.9821 & 0.9667 & 0.9 & 0.9 & 0.9806 \\
\hline $\mathrm{T}_{61-64}$ & 0.9859 & 0.9999 & 0.9999 & 1.0 & 1.1 & 0.9 & 0.9 & 1.005 \\
\hline$T_{65-66}$ & 1.1 & 1.1 & 1.1 & 1.1 & 1.1 & 0.9 & 0.9 & 1.0043 \\
\hline$T_{68-69}$ & 1.1 & 1.1 & 1.1 & 1.1 & 0.9257 & 0.9 & 0.9 & 0.9569 \\
\hline $\mathrm{T}_{80-81}$ & 0.9789 & 1.1 & 1.1 & 0.9766 & 1.1 & 0.9 & 0.9 & 0.9915 \\
\hline $\mathrm{Q}_{\mathrm{sc5}}$ & 0.0 & 0.0 & 0.0 & 0.0 & 0.0 & 0.0000 & 0.0 & -0.2340 \\
\hline $\mathrm{Q}_{\text {sc34 }}$ & 0.0 & 0.0 & 0.0 & 0.0 & 0.0 & 0.0017 & 0.14 & 0.0007 \\
\hline $\mathrm{Q}_{\mathrm{sc} 37}$ & 0.0 & 0.0 & 0.0 & 0.0 & 0.0 & 0.0000 & 0.0 & 0.0 \\
\hline $\mathrm{Q}_{544}$ & 0.0 & 0.0 & 0.0 & 0.0 & 0.0 & 0.0007 & 0.1 & 0.0566 \\
\hline $\mathrm{Q}_{\mathrm{sc45}}$ & 0.0 & 0.0 & 0.0 & 0.0 & 0.0 & 0.0009 & 0.1 & 0.0979 \\
\hline $\mathrm{Q}_{\mathrm{sc46}}$ & 0.0 & 0.0 & 0.0 & 0.0 & 0.0 & 0.0019 & 0.1 & 0.0467 \\
\hline $\mathrm{Q}_{\mathrm{sc48}}$ & 0.0 & 0.0 & 0.0 & 0.0 & 0.0 & 0.0007 & 0.15 & 0.0015 \\
\hline $\mathrm{Q}_{\text {sc74 }}$ & 0.0 & 0.0 & 0.0 & 0.0 & 0.0 & 0.0008 & 0.12 & 0.0080 \\
\hline $\mathrm{Q}_{\text {sc79 }}$ & 0.0 & 0.0 & 0.0 & 0.0 & 0.0 & 0.0009 & 0.1604 & 0.1992 \\
\hline $\mathrm{Q}_{\mathrm{sc} 82}$ & 0.0 & 0.0 & 0.0 & 0.0 & 0.0 & 0.0005 & 0.1604 & 0.2000 \\
\hline $\mathrm{Q}_{\mathrm{sc} 83}$ & 0.0 & 0.0 & 0.0 & 0.0 & 0.0 & 0.0013 & 0.1 & 0.0741 \\
\hline$Q_{s c 105}$ & 0.0 & 0.0 & 0.0 & 0.0 & 0.0 & 0.0008 & 0.1604 & 0.1991 \\
\hline $\mathrm{Q}_{\mathrm{sc} 107}$ & 0.0 & 0.0 & 0.0 & 0.0 & 0.0 & 0.0013 & 0.06 & 0.0 \\
\hline$Q_{s c 110}$ & 0.0 & 0.06 & 0.06 & 0.0 & 0.06 & 0.0028 & 0.06 & 0.0294 \\
\hline$P_{\text {loss }}(M W)$ & 111.7172 & 113.7233 & 113.7233 & 112.8162 & 112.6259 & 167.0409 & 107.9321 & 105.4821 \\
\hline CKHA [44] & $\begin{array}{l}\text { PSO-TVIW } \\
\text { [45] }\end{array}$ & $\begin{array}{l}\text { PSO-TVAC } \\
{[45]}\end{array}$ & $\begin{array}{l}\text { SPSO- } \\
\text { TVAC [45] }\end{array}$ & $\begin{array}{l}\text { PSO-CF } \\
{[45]}\end{array}$ & $\begin{array}{l}\text { PG-PSO } \\
{[45]}\end{array}$ & $\begin{array}{l}\text { SWT-PSO } \\
{[45]}\end{array}$ & $\begin{array}{l}\text { PGSWT- } \\
\text { PSO [45] }\end{array}$ & $\begin{array}{l}\text { IPG-PSO } \\
{[45]}\end{array}$ \\
\hline 110.79 & 116.8976 & 124.3335 & 116.2026 & 115.6469 & 116.6075 & 124.1476 & 119.4271 & 115.0605 \\
\hline GSA [46] & OGSA [47] & $\begin{array}{l}\text { CLPSO } \\
{[48]}\end{array}$ & EMA [49] & $\begin{array}{l}\text { NGBWCA } \\
{[39]}\end{array}$ & WCA [39] & $\begin{array}{l}\text { SARCGA } \\
{[18]}\end{array}$ & HEP [18] & $\begin{array}{l}\text { QOTLBO } \\
{[18]}\end{array}$ \\
\hline 127.76 & 126.99 & 130.96 & 126.22 & 121.47 & 131.83 & 113.12 & 115.58 & 112.2789 \\
\hline TLBO [18] & FPA [18] & CSA [18] & SSA [18] & MSSA [18] & $\begin{array}{l}\text { HSSSA } \\
{[18]}\end{array}$ & SSO [18] & ISSO [18] & MSFS [50] \\
\hline 116.4003 & 129.6524 & 121.2732 & 125.8324 & 124.0818 & 126.6992 & 179.1816 & 114.5297 & 114.6251 \\
\hline $\begin{array}{l}\text { SARCGA } \\
{[51]}\end{array}$ & HEP [51] & ALO [19] & IALO [19] & & & & & \\
\hline 113.12 & 115.58 & 116.86 & 114.795 & & & & & \\
\hline
\end{tabular}

case 2 , thus resulting in a reduction of power loss by $20.36 \%$, which is the best obtained result among all the algorithms reported in the literature till date. Thus, it has proved to be the most efficient among all the reported algorithms in 


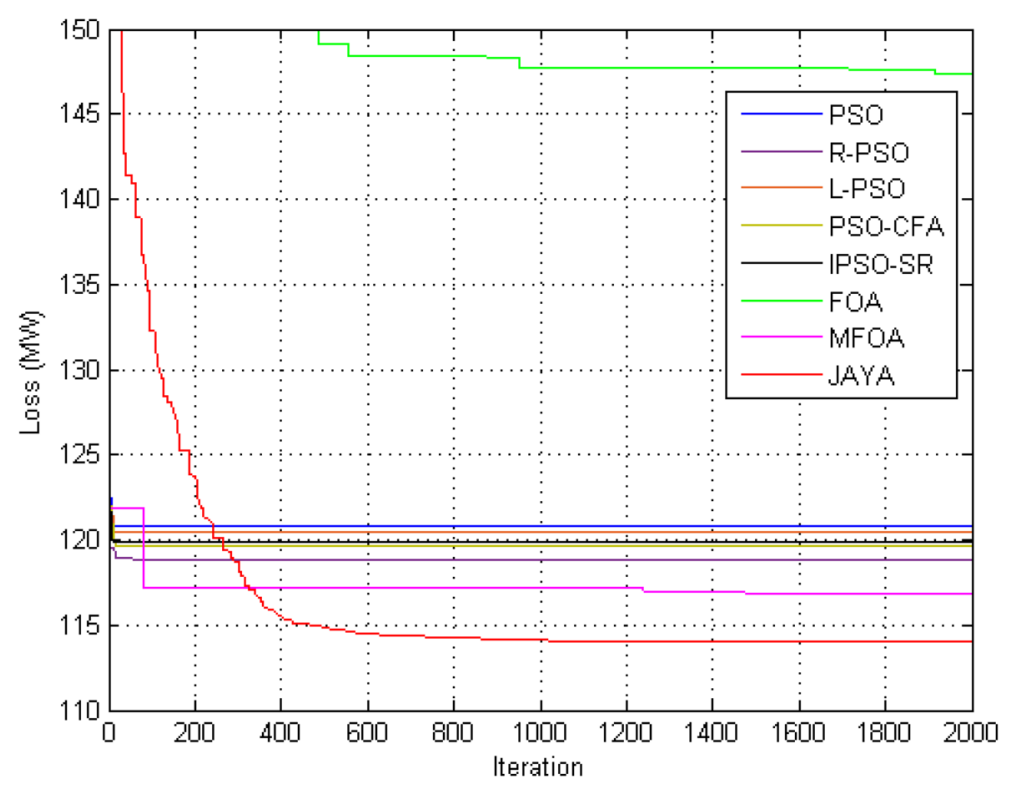

Fig. 7 Convergence characteristic of the algorithms for IEEE 118 bus system for case 1

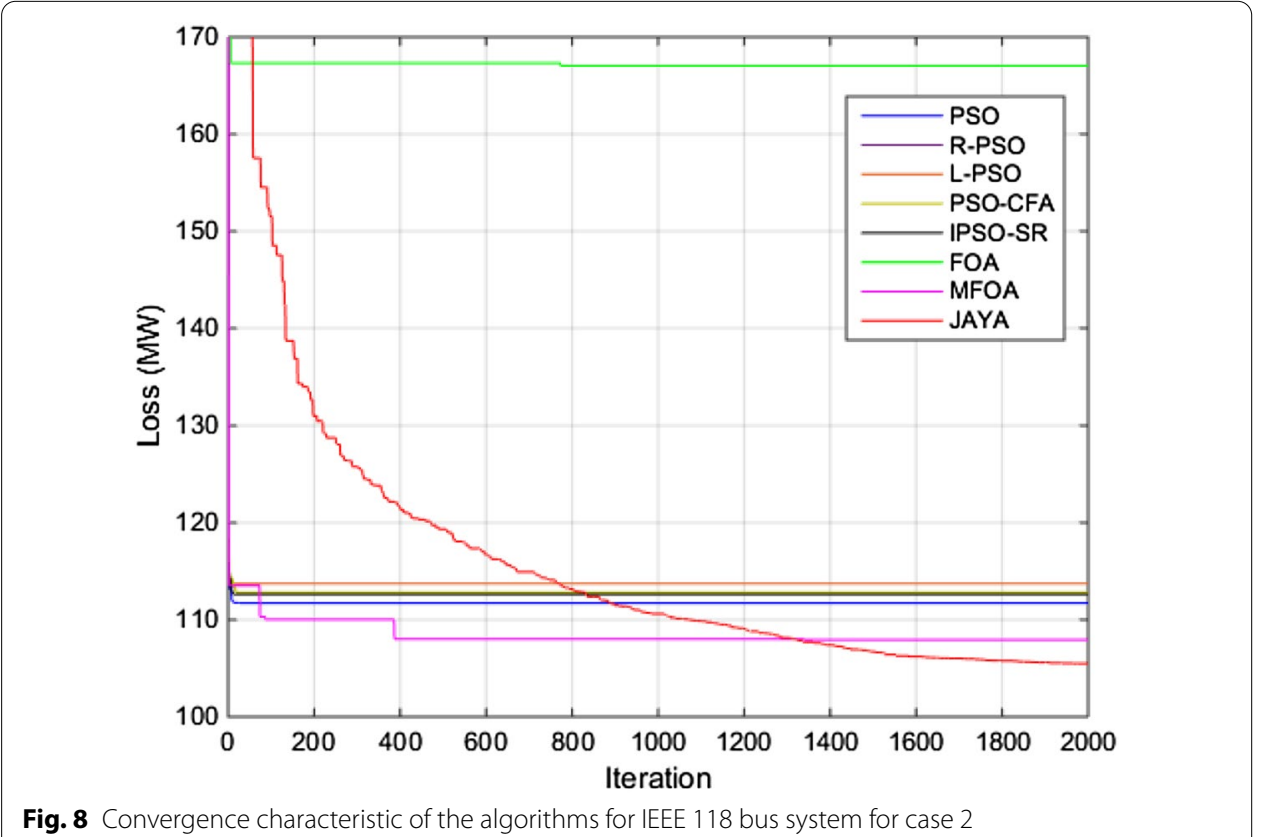

comparison as it is capable of determining the best solution for the highly nonlinear optimization problem of ORPD even for higher order bus system.

\section{Conclusion}

In this paper, a recently proposed optimization technique named JAYA algorithm has been used to solve the ORPD problem for determining the minimum power loss for the optimal location of the control variables. It has been applied on IEEE 14, 30, 57 and 118 bus systems and the algorithm proved to be the best among the others 
compared in the literature in terms of robustness, efficiency and consistency as it has the highest frequency of convergence within small range of optimal solution. It is a novel meta-heuristic algorithm, which jumps into its optimal solution very fast and accurately compared to the other reported algorithms. Thus, this algorithm is able to find best solution to the ORPD problem and has reduced the transmission line power loss largely and most significantly compared to others under the similar constraints. It has consistently obtained best results for all the mentioned four IEEE standard bus system for different cases with different combination of limits of the control variables. Hence, it can be concluded that the JAYA algorithm is one of the most efficient modern competitive tool for solving the optimization problem of ORPD for smaller and larger scale of power systems, and can give consistent results under any condition without violating any equality and inequality constraint. As a result this optimization technique can be used to solve real life problems in power system related to power or energy saving and cost saving and even other fields of engineering as it very much competent in obtaining satisfying results with high convergence rate with minimum deviation of results.

Acknowledgments

\section{Authors' contributions}

Mr. Tanmay Das carried out basic design, simulation work and prepared draft paper. Dr. Ranjit Roy and Dr. Kamal Krishna Mandal participated in checking simulation work, results and discussions, sequence of paper and helped to prepare the manuscript. All authors read and approved the final manuscript.

Funding

Not applicable.

Availability of data and materials

The datasets used and analyzed during the current study are available from the corresponding author on reasonable request.

\section{Declarations}

Competing interests

The authors declare that they have no competing interests.

Author details

${ }^{1}$ Department of Electrical Engineering, Chaibasa Engineering College, Chaibasa, Jharkhand, India. ${ }^{2}$ Department of Power Engineering, Jadavpur University, Salt Lake Campus, Kolkata, India.

Received: 14 January 2020 Accepted: 26 October 2021

Published online: 14 December 2021

\section{References}

1. Khazali AH, Kalantar M (2011) Optimal reactive power dispatch based on harmony search algorithm. Int J Electr Power Energy Syst 33(3):684-692

2. Abaci K, Yamaçli V (2017) Optimal reactive-power dispatch using differential search algorithm. Electric Eng 99:213-225

3. Das T, and Roy R (2018) A novel algorithm for the Optimal Reactive Power Dispatch. In: 20th National Power Systems Conference (NPSC), IEEE, pp 1-6

4. Das T et al (2020) Optimal reactive power dispatch incorporating solar power using jaya algorithm. In: Maharatna K, Kanjilal M, Konar S, Nandi S, Das K (eds) Computational advancement in communication circuits and systems. Lecture Notes in Electrical Engineering, vol 575. Springer, Singapore, pp. 37-48

5. Weile DS, Michielssen E (1997) Genetic algorithm optimization applied to electromagnetics: a review. IEEE Trans Antennas Propag 45(3):343-353

6. Devaraj D (2007) Improved genetic algorithm for multi-objective reactive power dispatch problem. Eur Trans Electr Power 17(6):569-581

7. Kennedy J, Eberhart R (1995) Particle swarm optimization (PSO). In: Proceedings of IEEE international conference on neural networks, Perth, Australia, pp 1942-1948 
8. Wu QH, Ma JT (1995) Power system optimal reactive power dispatch using evolutionary programming. IEEE Trans Power Syst 10(3):1243-1249

9. Das B, Patvardhan C (2007) A new hybrid evolutionary strategy for reactive power dispatch. In: 11th National conference on power systems. IISc, Bangalore, pp 358-363

10. Dai C, Chen W, Zhu Y, Zhang X (2009) Seeker optimization algorithm for optimal reactive power dispatch. IEEE Trans Power Syst 24(3):1218-1231

11. Tripathy M, Mishra S (2007) Bacteria foraging-based solution to optimize both real power loss and voltage stability limit. IEEE Trans Power Syst 22(1):240-248

12. Duman S, Sönmez Y, Güvenç U, Yörükeren N (2012) Optimal reactive power dispatch using a gravitational search algorithm. IET Gener Transm Distrib 6(6):563-576

13. Abou El Ela AA, Abido MA, Spea SR (2011) Differential evolution algorithm for optimal reactive power dispatch. Electr Power Syst Res 81:458-464

14. Ayan K, Kilic U (2012) Artificial Bee Colony algorithm solution for optimal reactive power flow. Appl Soft Comput 12:1477-1482

15. Ben Oualid Medani K, Sayah S, Bekrar A (2018) Whale optimization algorithm based optimal reactive power dispatch: a case study of the Algerian power system. Electric Power Syst Res 163:696-705

16. Shaheen AM, El-Sehiemy RA, Farrag SM (2016) Integrated strategies of backtracking search optimizer for solving reactive power dispatch problem. IEEE Syst J 12(1):424-433

17. Lenin K (2019) Enhanced red wolf optimization algorithm for reduction of real power loss. In: Smart intelligent computing and applications. Springer, Singapore, pp 45-51

18. Nguyen TT, Vo DN (2019) Improved social spider optimization algorithm for optimal reactive power dispatch problem with different objectives. Neural Comput Appl, 1-32

19. Li Z, Cao Y, Dai LV, Yang X, Nguyen TT (2019) Finding solutions for optimal reactive power dispatch problem by a novel improved antlion optimization algorithm. Energies 12(15):2968

20. Mei RNS, Sulaiman MH, Daniyal H, Mustaffa Z (2018) Application of Moth-flame optimizer and ant lion optimizer to solve optimal reactive power dispatch problems. J Telecommun Electron Comput Eng 10(1-2):105-110

21. Venkata Rao R (2016) Jaya: a simple and new optimization algorithm for solving constrained and unconstrained optimization problems. Int J Ind Eng Comput 7:19-34

22. Ghatak SR, Sannigrahi S, Acharjee P (2017) Comparative performance analysis of DG and DSTATCOM using improved PSO based on success rate for deregulated environment. IEEE Syst J 12(3):2791-2802

23. Pan WT (2012) A new fruit fly optimization algorithm: taking the financial distress model as an example. Knowl-Based Syst 26:69-74

24. Pan WT (2013) Using modified fruit fly optimisation algorithm to perform the function test and case studies. Connect Sci 25(2-3):151-160

25. Ghasemi M, Ghanbarian MM, Ghavidel S, Rahmani S, Moghaddam EM (2014) Modified teaching learning algorithm and double differential evolution algorithm for optimal reactive power dispatch problem: a comparative study. Inf Sci 278:231-249

26. Das T, Roy R (2018) Optimal reactive power dispatch using JAYA algorithm. In: IEEE international conference on emerging trends in electronic devices and computational techniques (EDCT), Kolkata, pp 1-6

27. Washington University. https://www2.ee.washington.edu/research/pstca/

28. Ghasemi M, Taghizadeh M, Ghavidel S, Aghaei J, Abbasian A (2015) Solving optimal reactive power dispatch problem using a novel teaching-learning-based optimization algorithm. Eng Appl Artif Intell 39:100-108

29. Zhao CXGB, Cao YJ (2005) A multi-agent based particle swarm optimization approach for optimal reactive power dispatch. IEEE Trans Power Syst 2:1070-1078

30. Zhang X, Chen W, Dai C, Cai W (2010) Dynamic multi-group self-adaptive differen-tial evolution algorithm for reactive power optimization. Electric Power EnergySyst 32:351-357

31. Ghasemi M, Ghavidel S, Ghanbarian MM, Habibi A (2014) A new hybrid algorithm for optimal reactive power dispatch problem with discrete and continuous control variables. Appl Soft Comput 22:126-140

32. Khorsandi A, Alimardani A, Vahidi B, Hosseinian SH (2011) Hybrid shuffled frogleaping algorithm and Nelder-Mead simplex search for optimal reactive powerdispatch. IET Gener Transm Distrib 5:249-256

33. Li Y, Wang Y, Li B (2013) A hybrid artificial bee colony assisted differential evolution algorithm for optimal reactive power flow. Int J Electr Power Energy Syst 52:25-33

34. Nakawiro W, Erlich I, Rueda JL (2011) A novel optimization algorithm for opti-mal reactive power dispatch: a comparative study. In: Proceedings of the IEEE Germany Electric Utility deregulation and restructuring and power technologies (DRPT) conference, pp 1555-1561

35. Villa-Acevedo W, López-Lezama J, Valencia-Velásquez J (2018) A novel constraint handling approach for the optimal reactive power dispatch problem. Energies 11(9):2352

36. Mehdinejad M, Mohammadi-Ivatloo B, Dadashzadeh-Bonab R, Zare K (2016) Solution of optimal reactive power dispatch of power systems using hybrid particle swarm optimization and imperialist competitive algorithms. Int J Electr Power Energy Syst 83:104-116

37. Mouassa S, Bouktir T (2019) Multi-objective ant lion optimization algorithm to solve large-scale multi-objective optimal reactive power dispatch problem. COMPEL-Int J Comput Math Electr Electron Eng 38(1):304-324

38. Abaci K, Yamaçli V (2017) Optimal reactive-power dispatch using di erential search algorithm. Electr. Eng. 99:213-225

39. Heidari AA, Abbaspour RA, Jordehi AR (2017) Gaussian bare-bones water cycle algorithm for optimal reactive power dispatch in electrical power systems. Appl Soft Comput 57:657-671

40. Anbarasan P, Jayabarathi T (2017) Optimal reactive power dispatch problem solved by an improved colliding bodies optimization algorithm. In: Proceedings of the 2017 IEEE international conference on environment and electrical engineering, Milan, Italy, 6-9 June 2017; pp 1-6

41. Mei RNS, Sulaiman MH, Musta Z, Daniyal H (2017) Optimal reactive power dispatch solution by loss minimization using moth-flame optimization technique. Appl. Soft Comput. 59:210-222 
42. Jeyadevi S, Baskar S, Babulal CK, Willjuice-Iruthayarajan M (2011) Solving multi-objective optimal reactive power dispatch using modified NSGA-II. Electric. PowerEnergy Syst. 33:219-228

43. Andersen MS, Hansson A, Vandenberghe L (2014) Reduced-complexity semidefinite relaxations of optimal power flow problems. IEEE Trans Power Syst 29:1855-1863

44. Mukherjee A, Mukherjee V (2016) Chaotic krill herd algorithm for optimal reactive power dispatch considering FACTS devices. Applied Soft Comput 44:163-190

45. Polprasert J, Ongsakul W, Dieu VN (2016) Optimal reactive power dispatch using improved pseudo-gradient search particle swarm optimization. Electric Power Components Syst 44(5):518-532

46. Duman S, Sonmez Y, Guvenc U, Yorukeren N (2012) Optimal reactive power dispatch using a gravitational search algorithm. IET Gener Transm Distrib 6:563-576

47. Shaw B, Mukherjee V, Ghoshal S (2014) Solution of reactive power dispatch of power systems by an opposition-based gravitational search algorithm. Int J Electr Power Energy Syst 55:29-40

48. Mahadevan K, Kannan P (2010) Comprehensive learning particle swarm optimization for reactive power dispatch. Appl Soft Comput 10:641-652

49. Rajan A, Malakar T (2016) Exchange market algorithm based optimum reactive power dispatch. Appl Soft Comput 43:320-336

50. Nguyen TT, Vo DN, Tran HV, Dai LV (2019) Optimal dispatch of reactive power using modified stochastic fractal search algorithm. Complexity 2019

51. Subbaraj P, Rajnarayanan PN (2009) Optimal reactive power dispatch using self-adaptive real coded genetic algorithm. Electr Power Syst Res 79:374-381

\section{Submit your manuscript to a SpringerOpen ${ }^{\circ}$} journal and benefit from:

- Convenient online submission

- Rigorous peer review

- Open access: articles freely available online

- High visibility within the field

Retaining the copyright to your article

Submit your next manuscript at $\boldsymbol{\nabla}$ springeropen.com 